\title{
Deubiquitylases in developmental ubiquitin signaling and congenital diseases
}

\author{
Mohammed A. Basar $\mathbb{D}^{1} \cdot$ David B. Beck ${ }^{1,2} \cdot$ Achim Werner $\mathbb{B}^{1}$
}

Received: 16 October 2020 / Revised: 20 November 2020 / Accepted: 24 November 2020 / Published online: 17 December 2020

This is a U.S. government work and not under copyright protection in the U.S.; foreign copyright protection may apply 2020

\begin{abstract}
Metazoan development from a one-cell zygote to a fully formed organism requires complex cellular differentiation and communication pathways. To coordinate these processes, embryos frequently encode signaling information with the small protein modifier ubiquitin, which is typically attached to lysine residues within substrates. During ubiquitin signaling, a three-step enzymatic cascade modifies specific substrates with topologically unique ubiquitin modifications, which mediate changes in the substrate's stability, activity, localization, or interacting proteins. Ubiquitin signaling is critically regulated by deubiquitylases (DUBs), a class of $\sim 100$ human enzymes that oppose the conjugation of ubiquitin. DUBs control many essential cellular functions and various aspects of human physiology and development. Recent genetic studies have identified mutations in several DUBs that cause developmental disorders. Here we review principles controlling DUB activity and substrate recruitment that allow these enzymes to regulate ubiquitin signaling during development. We summarize key mechanisms of how DUBs control embryonic and postnatal differentiation processes, highlight developmental disorders that are caused by mutations in particular DUB members, and describe our current understanding of how these mutations disrupt development. Finally, we discuss how emerging tools from human disease genetics will enable the identification and study of novel congenital disease-causing DUBs.
\end{abstract}

\section{Facts}

- Deubiquitylases (DUBs) are a class of $\sim 100$ human enzymes that regulate ubiquitin signaling by processing ubiquitin precursors, hydrolyzing ubiquitin chains, and cleaving ubiquitin modifications from substrates.

- Intricate regulatory mechanisms ensure spatial and temporal regulation of DUB activity and substrate

Edited by G. Melino

Achim Werner

achim.werner@nih.gov

1 Stem Cell Biochemistry Unit, National Institute of Dental and Craniofacial Research, National Institutes of Health, Bethesda, MD 20892, USA

2 Metabolic, Cardiovascular and Inflammatory Disease Genomics Branch, National Human Genome Research Institute, National Institutes of Health, Bethesda, MD 20892, USA recruitment to allow DUBs to integrate signals during development and coordinate developmental cell-fate decision.

- DUBs regulate gene expression (through deubiquitylating histones and modulating the stability of chromatin regulators/transcription factors) and signaling pathways to control metazoan development.

- Mutations in particular DUBs cause developmental disorders, but the molecular mechanisms and cognate substrates or E3 ligases are often unknown.

- Many DUBs are intolerant to haploinsufficiency and missense mutations in the general human population, suggesting that their dysregulation likely causes developmental diseases.

\section{Open questions}

- How are specific DUBs regulated during embryonic and postnatal development to achieve their functions in cellfate determination?

- What are the mechanisms and substrates of DUBs whose mutations underlie developmental diseases? 
- Which other DUBs cause developmental diseases? Can we utilize tools from human genetics to identify these DUBs and study their (patho-)physiological functions and mechanisms?

\section{Introduction: the ubiquitin code and DUBs in early development}

During metazoan development, stem cells of the embryo undergo self-renewal, commit to differentiation programs, and produce and react to signaling molecules to ensure proper formation of specialized cell types, tissues, and organs. The precise execution of these processes is often controlled by ubiquitylation, an essential posttranslational modification (PTM) that regulates the stability, activity, localization, or interaction landscape of substrates [1-3]. The differential outcomes of ubiquitylation are accomplished by elaborate enzymatic cascades that synthesize ubiquitin signals, which are covalently linked to substrates and recognized and interpreted by various effector proteins (Fig. 1A) [4-6]. Research in recent decades has elucidated key principles of this ubiquitin code [4]. Substrates can either be modified with ubiquitin monomers or with structurally distinct ubiquitin polymers that are linked via the $\mathrm{N}$ terminus or one of the seven internal lysine residues (K6, K11, K27, K29, K33, K48, K63). These ubiquitin polymers can be homotypic (chains with only one linkage type) or heterotypic (chains with at least 2 different linkage types) [7]. Mono- or multi-monoubiquitylation of substrates often result in changes in the interaction landscape of the modified protein and play important roles during e.g., transcription, translation, and endosomal sorting [8-11]. Modification of substrates with homotypic and heterotypic ubiquitin polymers elicits various downstream effects, which depend on the linkage type(s) and architecture of the ubiquitin chain. Well established examples with relevance to this review include homotypic K11- or K48-linked chains

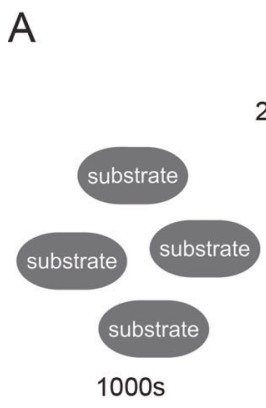

B

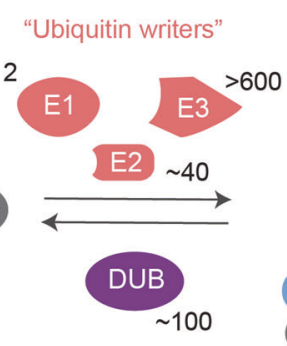

"Ubiquitin erasers"

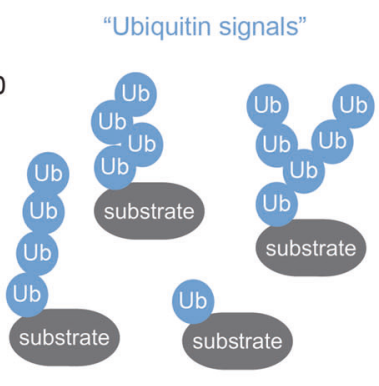

Cleavage modes of DUBs

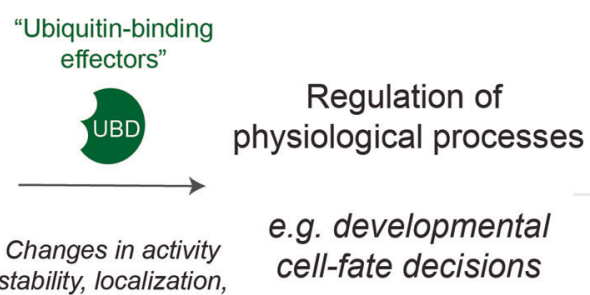

cell-fate decisions
Position-specific cleavage

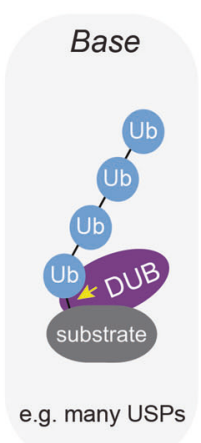

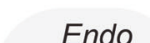

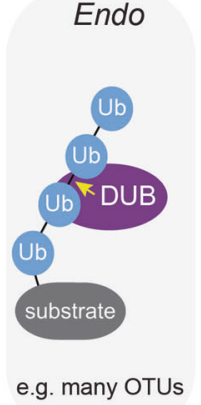

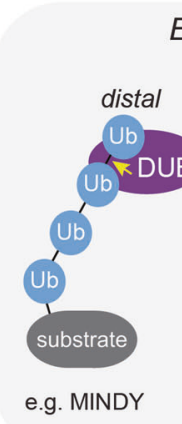

Exo

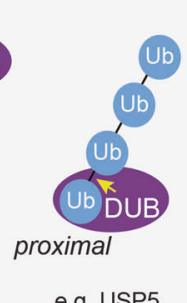

Linkage-specific cleavage

e.g. K63 chain

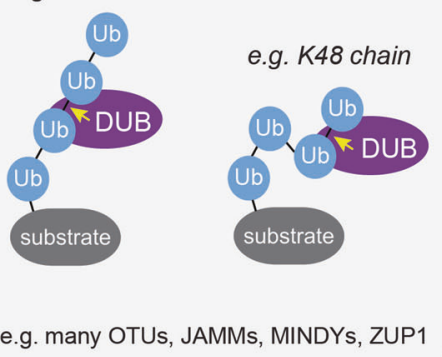

Fig. 1 Overview of how ubiquitin signaling regulates developmental cell-fate decisions and cleavage modes of DUBs. A To initiate ubiquitin signaling, an enzymatic cascade, consisting of ubiquitin E1 activating, E2 conjugating, and E3 ligating enzymes, decorates substrates with topologically different ubiquitin modifications. Effector proteins containing various ubiquitin-binding domains (UBDs) interpret the ubiquitin signals and mediate changes in the substrate activity, stability, localization or interacting proteins. This controls cellular behavior during many physiological processes, including development. DUBs are important regulators of this ubiquitin code by reversing ubiquitin modifications, thus modulating or terminating signaling. B Cartoons depicting different position- and linkage-specific cleavage modes by which DUBs can act on their substrates. The yellow arrow indicates the peptide/isopeptide bond that is hydrolyzed in each example. 
that mediate degradation via the $26 \mathrm{~S}$ proteasome $[12,13]$, homotypic M1- or K63-linked chains that allow for formation of signaling complexes during NF-kB activation [14, 15] and DNA repair [16-18], and homotypic K63linked chains that mediate autophagic degradation of protein complexes, aggregates, and damaged organelles [19].

Ubiquitylation regulates biological pathways in a highly specific and reversible manner, which enables ubiquitin signaling to control cellular behavior and decision-making during embryonic development $[1,3]$. Specificity is achieved by more than 600 ubiquitin E3 ligases, which bind distinct sets of substrates and cooperate with $2 \mathrm{E} 1$ and 40 E2 enzymes to mediate transfer of ubiquitin monomers or chains to thousands of cellular substrates $[4,20,21]$. Reversibility is ensured by $\sim 100$ human deubiquitylases (DUBs), a family of enzymes that processes ubiquitin precursors, edits chain architecture, or cleaves ubiquitin signals from substrates. Through these activities, DUBs maintain a functional ubiquitin pool for conjugation and modulate or terminate signaling responses [1, 22-24].

DUBs can deubiquitylate a broad range of substrates in fundamental cellular processes including transcription, translation, cell cycle progression, vesicular trafficking, autophagy, proteasomal degradation, and intracellular signaling to control various aspects of stem cell maintenance, differentiation, and development [1, 3, 25-30]. Consistent with these essential functions, genetic deletion of a number of DUBs are embryonic, early postnatal, or perinatal lethal in mice (examples discussed in this review include USP7 [31], USP8 [32], USP9X [33, 34], USP16 [35], USP22 [36], BAP1 [37], OTUB1 [38], $A M S H$ [39], OTUD6B [40], and OTUD5 [41, 42]) and kockdown of tens of DUBs has been shown to be lethal or to cause severe defects during zebrafish development $[43,44]$. It is therefore not surprising that dysregulation of DUBs is linked to many human diseases, including cancer, neurodegeneration, and inflammatory syndromes [1, 25-28, 45-47]. A growing number of studies has also implicated aberrant activities of several DUBs as drivers of distinct congenital diseases (Table 1), providing further evidence for essential roles for these enzymes in controlling ubiquitin signaling during embryonic and postnatal development.

Here, we review structural, functional, and regulatory features of DUBs that allow this class of enzymes to fulfill their roles during development. We summarize general mechanisms of how DUBs regulate stem cell self-renewal and differentiation processes and our current understanding of how mutations in particular DUBs cause congenital diseases. Finally, we discuss how recently developed genetic resources can help identify candidate DUBs critical for development.

\section{Structural and functional features of DUBs}

\section{DUB families}

Since the discovery of DUBs in the mid-1980s [48-50], extensive studies have defined them as a structurally diverse set of $\sim 100$ human proteases that can be divided into two groups according to their enzymatic mechanisms. First, zinc-dependent JAB1/MPN/MOV34 (JAMM) metalloproteases (12 human members) and second papain-like cysteine proteases that, based on their catalytic domain, are further subclassified into six families: ubiquitin-specific proteases (USPs, 56 members), ovarian tumor proteases (OTUs, 17 human members), ubiquitin carboxy-terminal hydrolases (UCHs, 4 human members), the Machado-Joseph disease proteases (MJDs, 4 human members), and two more recently identified families, the motif interacting with ubiquitin-containing novel DUB family (MINDYs [51], 5 human members) and zinc finger containing ubiquitin peptidase 1 family (ZUP1, 1 human member [52-55]). Eleven of these 99 DUBs have lost critical catalytic residues and are thought to be catalytically inactive [56].

\section{DUBs can remove ubiquitin from substrates or cleave ubiquitin-linkages}

Several in-depth discussions on DUB enzymology, structure, and substrate specificity have recently been published and we refer interested readers to these seminal reviews [22, 27, 57-60]. To provide the mechanistic framework for the role of DUBs in development, we highlight a few general structural and functional properties of DUBs.

To maintain free ubiquitin pools for conjugation and to regulate ubiquitin signaling, DUBs hydrolyze peptide or isopeptide bonds between ubiquitin and a substrate or within ubiquitin chains. In this process, DUBs generally utilize their catalytic domain to recognize and remove the distal (C-terminal glycine-contributing) ubiquitin from the proximal (lysine- or methionine-contributing) ubiquitin or the substrate. By utilizing additional ubiquitin-binding sites and/ or substrate interaction motifs, DUBs have evolved specificities for cleavage at particular positions in the ubiquitin chain or linkage types [22, 27, 57-59] (Fig. 1B). For instance, many DUBs of the USP family encode substrate interaction motifs and cleave ubiquitin chains from substrates (base cleavage) [22], while other DUBs prefer to cleave ubiquitin chains from the middle (endo-cleavage, e.g., most OTU DUBs [61]) or from the distal or proximal end of the chain (distal exo cleavage, e.g., MINDY [51, 62], and proximal exo-cleavage, e.g., USP5 [63], respectively). In addition, some DUBs display exquisite linkage specificity (e.g., some members of the OTUs [61], JAMMs [64-66], 


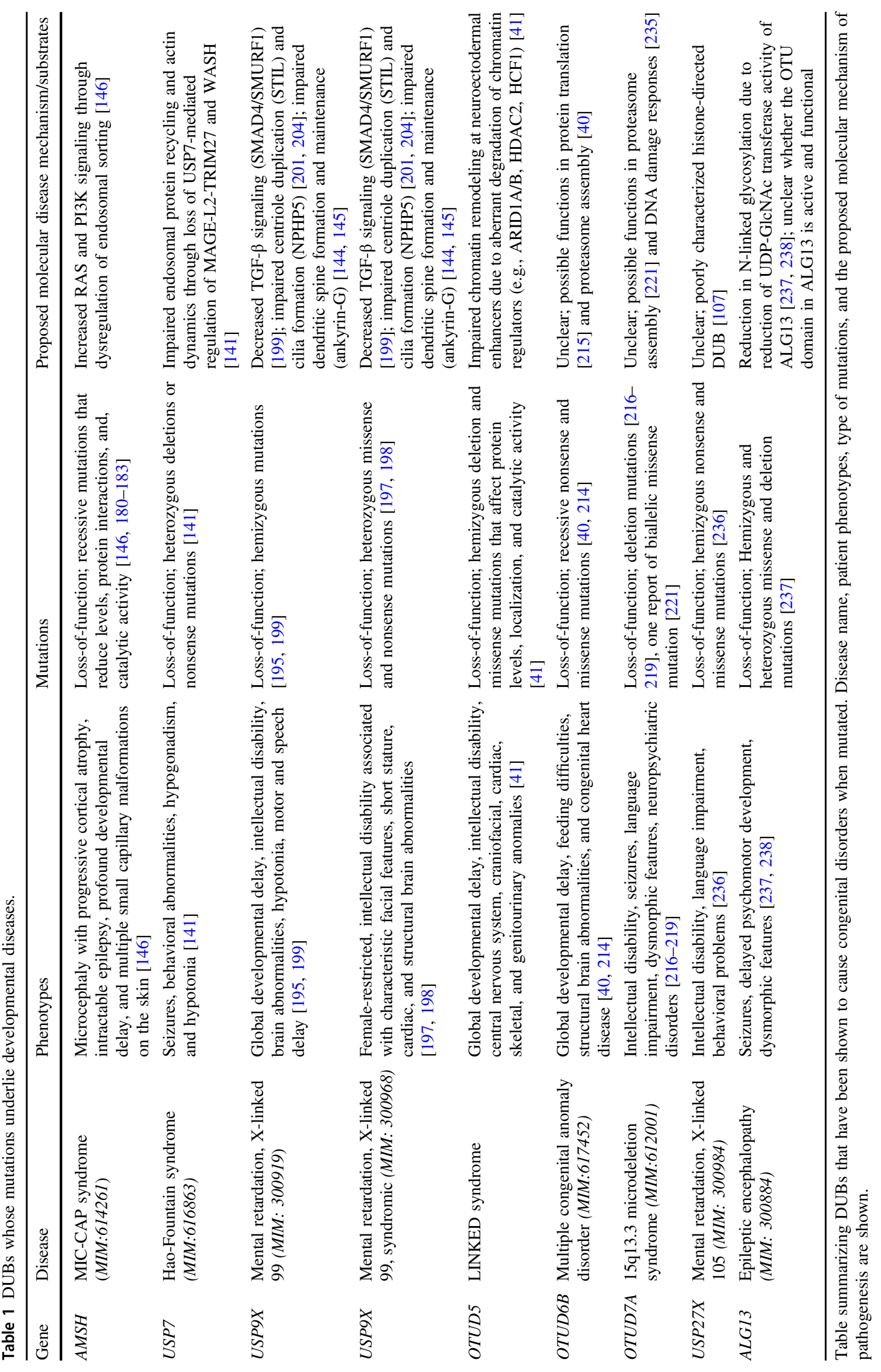


MINDYs [51], ZUP1 [52-55] and the USPs USP30 [67-69] and CYLD [70,71]) and only cleave one or a distinct set of ubiquitin-linkage types, while other DUBs (e.g., most USPs [72]) are more promiscuous.

\section{Regulatory principles impinging on DUBs}

Ubiquitylation frequently orchestrates core signaling networks essential for stem cell maintenance and differentiation. During these processes, it is important that ubiquitin signals are tightly controlled. Similar to their E3-ligase counterparts [1, 3, 73, 74], DUBs are subject to a plethora of regulatory principles that impinge on their abundance, localization, activity, and substrate recruitment, thus allowing temporal and spatial regulation of deubiquitylation [26-28, 59, 75]. Here, we will briefly summarize key mechanisms of DUB regulation highlighting examples that are recent and have particular relevance for development.

\section{Regulation of DUB abundance}

During development, similar to other signaling proteins, DUBs are commonly controlled at the level of their synthesis and degradation [11, 76-78]. For instance, two histone-directed DUBs, USP44 and USP22, are antagonistically regulated in their mRNA expression to ensure faithful stem cell differentiation [79-81]. In addition, transcription of other DUBs is upregulated at stages of differentiation or in specialized cell types when they are functionally required (e.g., ATXN3, UCHL1, and OTUD7A in neuronal cells and in the brain [77, 82-90]). Besides transcriptional control, DUBs are also frequently subject to regulated ubiquitin-dependent degradation. This process can be induced by stimulus-dependent proteolytic processing (as e.g., shown for CYLD [91, 92], A20 [93], and USP1 [94, 95]) and some DUBs can counteract their own degradation via auto-deubiquitylation. For example, phosphorylation of USP4 by AKT activates and thus stabilizes this DUB, a process required for proper regulation of TGF- $\beta$ signaling during embryonic development (further discussed below) [96, 97]. Taken together, transcriptional and posttranslational mechanisms cooperate to enable adjustment of the cellular DUB repertoire required for a particular developmental process or tissue function.

\section{Regulation of DUB localization}

Another frequent mode of regulation in eukaryotic cells is targeted localization [98]. Experiments in mammalian tissue culture cells analyzing GFP-tagged DUBs by fluorescence microscopy have revealed that at steady-state conditions, specific DUBs are localized to distinct sites such as the cytoplasm, nucleus, select organelles, or cellular membranes [99]. These subcellular localizations can be modulated through various mechanisms. First, a number of DUBs are expressed as multiple splice variants, which can encode domains that allow for isoform-specific subcellular localization and function. Examples include USP19 (cytosolic and ER [100, 101]), USP33 (ER and Golgi [102]), and USP35 (cytosolic, ER, and lipid droplets [103]). Second, several DUBs are shuttled between the nucleus and cytoplasm via reversible PTMs [96, 97, 104, 105]. For instance, AKT-mediated phosphorylation relocates nuclear USP4 to the cytoplasm and membranes to regulate TGF $\beta$ signaling during embryonic stem cell differentiation [96, 97]. In addition, UBE2O-mediated multi-monoubiquitylation of BAP1 sequesters this DUB to the cytoplasm during adipocyte differentiation [105]. Third, many DUBs are recruited to their substrates with the help of adapter proteins. This regulatory concept is frequently applied by histone-directed DUBs. For example, USP44 (through the N-CoR complex [106]), USP51, USP27X, and USP22 (through ATXN7L3 and ENY2 [107]), and BAP1 (through FOXK1/2 and ASXL1/2/3 [37, 108, 109]) are recruited to specific regions on chromatin, where they counteract monoubiquitylation of $\mathrm{H} 2 \mathrm{~A}$ and $\mathrm{H} 2 \mathrm{~B}$ to regulate gene expression changes required for various aspects of stem cell maintenance and differentiation (see below). In addition, DUB recruitment to substrates via adapter proteins can also be utilized to stabilize transcription factors. This is exemplified by USP7, which has recently been shown to be targeted to stemness factors SOX2, NANOG, and OCT4 via BACH1 to counteract their degradative ubiquitylation, thus ensuring hESC self-renewal [110]. Taken together, various mechanisms control the dynamic localization of DUBs to enable spatial restriction of ubiquitin signaling during development.

\section{Regulation of DUB activity and substrate recruitment}

In addition to control of abundance and localization, DUBs are also subject to regulation at the level of their activity and substrate recruitment (reviewed in detail in [22, 28, 59, 75]). We will briefly outline these principles in the following section by describing their relevance in ubiquitin signaling during developmental cell-fate decisions.

\section{Regulation of DUB activity through interactions in cis or trans}

Catalytic activities of DUBs can be modified through interaction with accessory domains or proteins. For instance, ubiquitin-binding and activity of BAP1, an essential, histonedirected DUB that regulates gene expression networks during 
development [37, 111], is stimulated by binding to the transcription regulators ASXL1, ASXL2, or ASXL3 [111113]. This activation is critically controlled by monoubiquitylation of ASXL proteins [114]. In a different example, USP7, a DUB with pivotal roles in stem cell self-renewal and differentiation (see below), requires its C-terminal ubiquitin-like domains to fold onto the catalytic USP domain $[115,116]$ resulting in increased intrinsic USP7 activity, which can be further stimulated by binding of an interacting protein in the form of GMP-synthase [115, 117]. Similarly, the interaction of UAF1 and WD-repeat-containing proteins with specific DUBs regulates their catalytic activity [118120]. One example is given by USP1, an important negative regulator of osteoblastic differentiation [121]. Such allosteric regulation is also well described for DUBs that are incorporated into large macromolecular complexes such as the proteasome [122-126] and the SAGA histone acetyltransferase complex [127-129] (i.e., USP22, an essential regulator of stem cell differentiation [36, 81]). Finally, also self-association of DUBs has been shown to regulate DUB activity. USP25, a regulator of the WNT signaling pathway [130], forms active dimers and autoinhibited tetramers in vitro and in cells [131-133]. Thus, various types of interactions in cis or trans can activate or inhibit the activity of DUBs that regulate important aspects of differentiation. However, in most cases, how these mechanisms are implemented to control ubiquitin signaling during embryonic and postnatal development remain unclear and will require further investigation.

\section{DUB interactions with E3s}

In addition to interacting with allosteric regulators, DUBs also frequently associate with ubiquitin E3 ligases in cells [134]. This coupling of opposing enzymatic activities has emerged as a functionally important feature that can regulate ubiquitin signaling in diverse and complex ways [135]. DUB-E3 interactions are used for mutual ubiquitindependent regulation (e.g., to control each other's stability, see above) or for editing ubiquitin chain architecture on particular substrates (as shown for the hybrid DUB/E3 enzyme A20 and CYLD-ITCH complexes during inflammatory signaling [136, 137]). Moreover, DUB-E3 complexes can work in direct opposition on shared substrates, thus fine-tuning responses during cell-fate decisions. For instance, USP9X associates with the ubiquitin E3-ligase WWP1 to modulate DVL2 ubiquitylation to specify canonical and noncanonical responses of WNT signaling, which controls various aspects of stem cell self-renewal and differentiation [138-140]. Similarly, USP7, an integral part of the ubiquitin E3-ligase complex MAGE-L2-TRIM27, acts as a molecular rheostat to control the activity of the actin nucleating protein WASH during neurodevelopment [141] (further discussed below), illustrating the exquisite regulation afforded by coupling opposing DUB and E3 activity during differentiation processes.

\section{Regulation by PTMs}

DUB catalytic activity can be further controlled by reversible PTMs such as phosphorylation, ubiquitylation, SUMOylation, or oxidation [28, 59]. Regulation of DUB activity by PTMs has been shown to control physiological processes such as DNA damage responses, cell cycle progression, and innate immune signaling [26, 59]; however, little is known how this regulatory principle is employed to control development. In contrast, multiple recent studies have demonstrated that substrate recruitment to DUBs is frequently regulated by phosphorylation to ensure faithful differentiation (Fig. 2). For instance, during osteoblast differentiation, USP15 recognizes and deubiquitylates its target, the transcription factor $\beta$-catenin, only upon $\beta$-catenin phosphorylation by MEKK2 [142]. Conversely, ERK1mediated phosphorylation of the pluripotency factor NANOG inhibits interactions with USP21, which results in proteasomal degradation of NANOG, thus facilitating rewiring of transcriptional networks during mESC differentiation [143]. In another example, USP9X undergoes TGF- $\beta$-induced phosphorylation, which does not affect its DUB activity but increases binding to its substrate ankyrin$\mathrm{G}$, resulting in ankyrin-G stabilization required for maintaining dendritic spines during neuronal differentiation [144, 145] (see further details below). Thus, during development, DUB-substrate interactions are frequently modulated by signal-induced phosphorylation, which allows DUBs to convert a particular signaling input into downstream cellular responses.

\section{Mechanisms how DUBs control development}

Several DUBs have been shown to control different aspects of embryonic development by diverse mechanisms. This includes AMSH and USP7, which regulate endosomal sorting and membrane trafficking required for faithful neuronal differentiation [141, 146] (see below) and USP8, which maintains high levels of autophagy in mESCs required for self-renewal and pluripotency [147]. Most commonly however, DUBs regulate stem cell maintenance and differentiation by controlling gene expression (through deubiquitylating histones or through stabilizing chromatin regulators and cellidentity-defining transcription factors) or by modulating developmental signaling pathways (Fig. 3). In the following, we will outline examples for each of these mechanisms. 


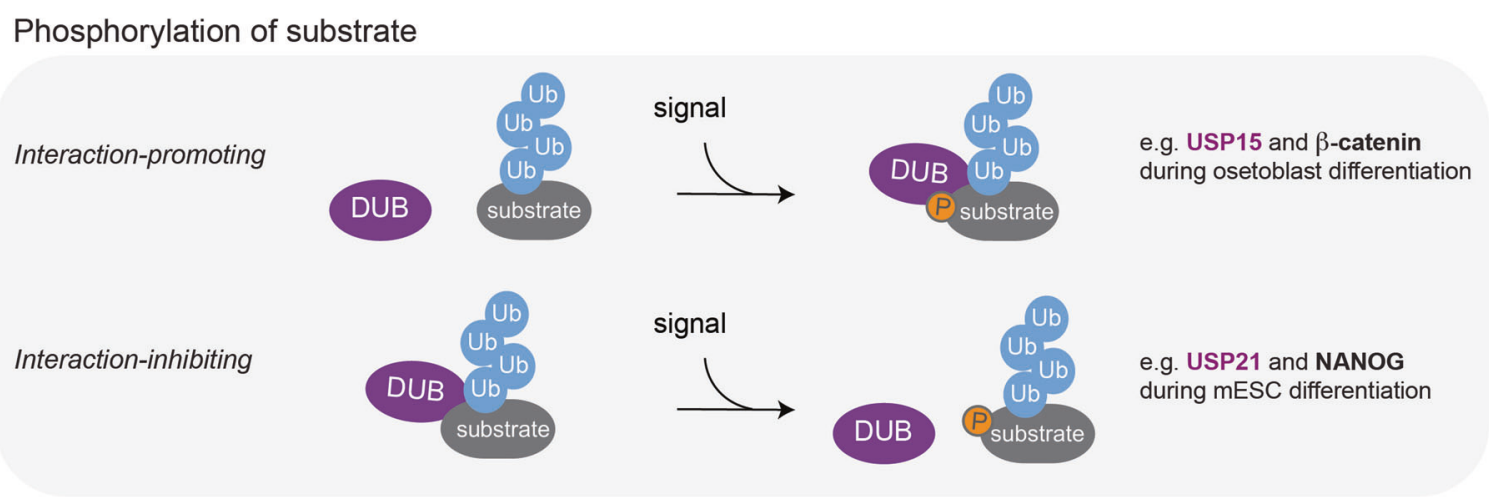

Phosphorylation of DUB

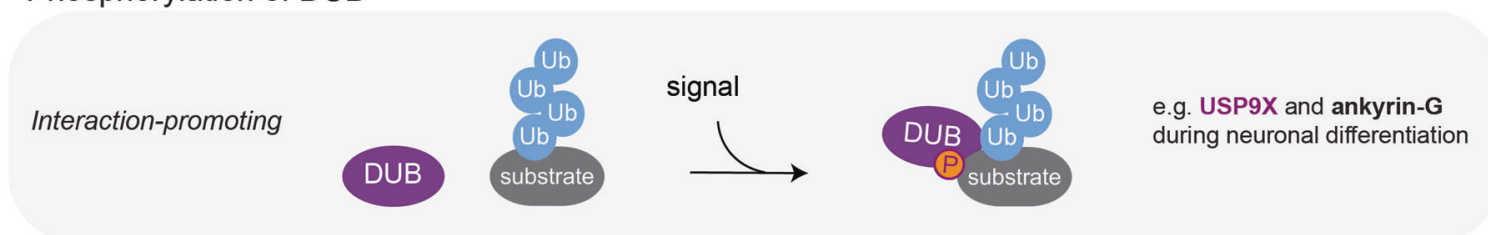

Fig. 2 Stimulus-induced phosphorylation regulates DUB-substrate recruitment during differentiation. Stimulus-induced phosphorylation is frequently used to regulate DUB-substrate recruitment during developmental cell-fate decisions. This can occur through interactionpromoting or -inhibiting substrate modification (upper panel).

\section{DUBs regulating development through deubiquitylating histones}

Dynamic changes in chromatin architecture are required for driving developmental gene expression programs. These changes are brought about by reversible histone PTMs, which alter the physical properties of chromatin and/or recruit effector proteins to alter transcription. Monoubiquitylation of $\mathrm{H} 2 \mathrm{~A}$ and H2B are an abundant and critical means for ensuring accurate gene expression during metazoan development $[1,27]$. Catalyzed by a family of multi-subunit E3 ligases known as Polycomb repressive complexes (PRC1), monoubiquitylation of $\mathrm{H} 2 \mathrm{~A}$ at $\mathrm{K} 119$ is generally thought to silence downstream genes [148-151]. Conversely, RNF20/RNF40-mediated monoubiquitylation of $\mathrm{H} 2 \mathrm{~B}$ at $\mathrm{K} 120$ is generally associated with activation of gene expression through recruiting enzymes that decorate $\mathrm{H} 3$ with activating methylation marks $[152,153]$. Several DUBs (including USP7, MYSM1, USP21, USP22, USP44, USP16, and BAP1 [79, 81, 111, 117, 143, 154-158]) have been proposed to reverse $\mathrm{H} 2 \mathrm{~A}$ and/or $\mathrm{H} 2 \mathrm{~B}$ ubiquitylation to control transcriptional networks during development (Fig. 3A). In this context, the mechanistic details of histone deubiquitylation and recruitment to chromatin have been wellcharacterized for only a subset of these DUBs (e.g., USP22 [107, 129, 159] and BAP1 [37, 108, 109, 111-114]). DUBs that have been reported to control developmental processes through deubiquitylating $\mathrm{H} 2 \mathrm{~B}$ include USP44, which represses genes involved in lineage commitment during mESC maintenance [79], and USP22, which specifically inhibits expression
Examples in which substrate phosphorylation promotes and inhibits DUB-substrate interaction include USP15- $\beta$-catenin and USP21NANOG, respectively. Stimulus-induced phosphorylation can also occur on DUBs to promote interactions with substrates (e.g., USP9Xankyrin $\mathrm{G}$, lower panel).

of the pluripotency factor SOX2 during hESC differentiation [81]. Examples of DUBs that are thought to elicit their functions through $\mathrm{H} 2 \mathrm{~A}$ deubiquitylation include BAP1, USP21, and USP16 [35, 37, 108, 111, 143, 160]. BAP1 and USP21 activity are required for stem cell self-renewal by ensuring the expression of genes that are involved in basic cellular functions and that are under the control of the pluripotency factor NANOG, respectively [108, 143]. In contrast, the Down Syndrome-associated USP16 is not essential for stem cell maintenance, but its activity was proposed to alleviate $\mathrm{H} 2 \mathrm{~A}$ ubiquitylation-imposed repression of lineage-specific genes during differentiation $[35,154,160]$. Thus, multiple DUBs likely cooperate to modulate chromatin accessibility and gene expression during development through counteracting $\mathrm{H} 2 \mathrm{~A} /$ H2B monoubiquitylation. In most cases, how such interplay is spatially and temporally regulated, remains to be determined.

\section{DUBs regulating development through controlling chromatin regulator and transcription factor stability}

In addition to controlling gene expression at the level of histone deubiquitylation, DUBs also frequently target chromatin regulators and transcription factors to modulate their stability and function during stem cell maintenance and differentiation [27, 41, 161] (Fig. 3A). For example, results from somatic reprogramming studies suggest that USP26 cleaves K48-linked ubiquitin chains from the chromobox-containing proteins $\mathrm{CBX} 4$ and $\mathrm{CBX} 6$ during 
A

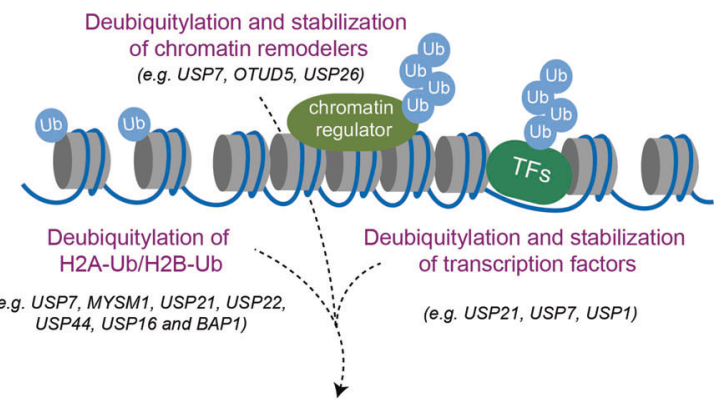

Changes in chromatin architecture \& transcription required for developmental cell fate decisions

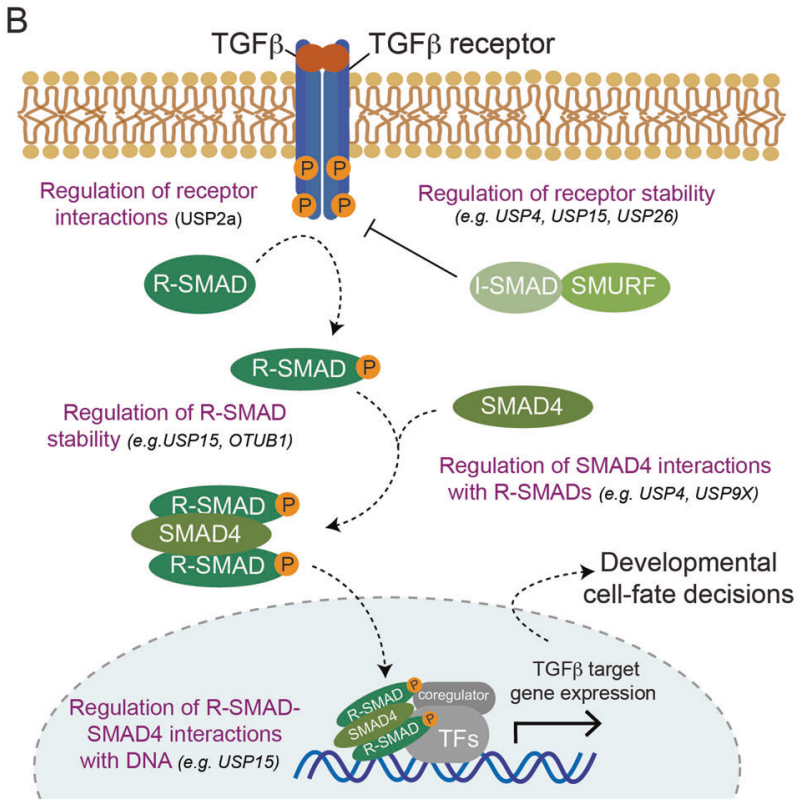

Fig. 3 Mechanisms of how DUBs regulate ubiquitin signaling to determine developmental cell-fate decisions. A Schematic overview of general principles of how DUBs controls differentiation processes. Several indicated DUBs have been proposed to target ubiquitylated histones, chromatin remodeling complexes, or master transcription factors (TFs) to bring about changes in transcriptional networks required for faithful development. B Schematic overview of how TGF$\beta$ signaling contributes to cell-fate determination during development highlighting regulatory concepts of how DUBs modulate the strength and duration of signaling responses. Binding of TGF- $\beta$ binding to the TGF- $\beta$ receptor leads to receptor kinase activation and phosphorylation of receptor-activated SMADs (R-SMADs). Phosphorylated RSMADs associate with SMAD4 to form active transcription factor complexes that translocate from the cytosol to the nucleus to elicit transcriptional responses required for developmental cell-fate decisions. This signaling cascade can be blocked by inhibitory SMADs (I-SMAD), which recruit the ubiquitin ligases SMURF1/2 (SMURF) to the TGF- $\beta$ family receptors for ubiquitin-mediated degradation. Also other TGF- $\beta$ signaling pathway components are subject to regulation by ubiquitylation, which is counteracted by DUBs as indicated.

mESC differentiation [162]. This was proposed to stabilize these proteins and promote their function in the context of the PRC1 complex to repress the expression of pluripotency genes, ensuring faithful lineage commitment. In addition, recent reports have shown that both, USP21 and USP7 counteract degradative ubiquitylation of NANOG to ensure self-renewal of ESCs $[110,143]$. This example showcases how several DUBs can target the same transcription factor and it will be interesting to further explore how such interplay regulates ESC maintenance (e.g., through targeting differently localized pools of NANOG). Conversely, the same DUB can also target several distinct transcription factors in a cell-type-specific manner. For instance, USP7, in addition to its function in maintaining hESCs [110], has been shown to control the stability of several other cellidentity-defining and lineage-promoting transcription factors, including (1) REST in neural progenitor cells to promote their maintenance [163, 164], (2) c-MYC in neural stem cells to promote their self-renewal [165], and (3) RUNX in skeletal stem cells to promote differentiation into osteoblasts [166]. Taken together, DUBs frequently target chromatin regulators or transcription factors in cell-type and tissue-specific contexts to control developmental cell-fate decisions.

\section{DUBs regulating development through modulating signaling pathways}

Multiple signaling pathways-such as FGF, Hedgehog, WNT, TGF- $\beta / B M P$, and Notch-orchestrate development, operating repeatedly at different times and regions in the embryo to regulate germ layer specification, patterning, and organogenesis [167]. These core pathways are critically controlled by ubiquitylation and many DUBs participate in this regulation [3, 46, 168-170]. Here, to highlight concepts of how DUBs can modulate these cascades, we will focus on TGF- $\beta /$ BMP signaling.

In the canonical pathway, secreted TGF- $\beta$ and BMP ligands elicit their functions by activating transmembrane serine/threonine kinase receptors and intracellular second messengers known as SMADs (Fig. 3B). Binding of TGF$\beta / \mathrm{BMP}$ ligands to their cognate receptors promotes their kinase activity, which leads to the phosphorylation of receptor-regulated SMADs (R-SMADs) [171]. Upon phosphorylation, both classes of R-SMADs associate with SMAD4 to form active transcription factor complexes that translocate from the cytoplasm to the nucleus, where they elicit downstream transcriptional responses. Finally, inhibitory SMADs such as SMAD7 are amongst TGF- $3 /$ BMPinduced genes and serve as scaffolds to recruit the ubiquitin E3 ligases SMURF1/2 to TGF- $\beta$ family receptors for ubiquitin-mediated degradation. In addition to this negative feedback regulation, reversible poly- and monoubiquitylation of virtually all components of the TGF- $\beta$ /BMP pathway have been shown to control the strength and duration of the signaling response. A number of DUBs participate in this regulation at multiple levels (Fig. 3B). First, several 
DUBs have been shown to regulate turnover of the TGF- $\beta$ receptor using diverse mode of actions. This includes DUBs that stabilize the receptor by deubiquitylation of the receptor (USP4 [96] and USP15 [172]) and by deubiquitylation-dependent inactivation of SMURF2 (USP15 [173]) or DUBs that promote receptor degradation through deubiquitylating and stabilizing SMAD7 (USP26 [174]). Second, DUBs regulate protein interactions of the TGF- $\beta$ receptor. This is exemplified by USP2a, which associates with the TGF- $\beta$ type I and II receptors to cleave K33-linked ubiquitin chains from them, thus promoting interactions with R-SMADs and enhancing downstream signaling [175]. Third, DUBs target ubiquitylated RSMADs to regulate their stability and interactions. For example, both, USP15 and OTUB 1 counteract degradative polyubiquitylation of activated R-SMADs to promote transcriptional downstream responses [176, 177]. This occurs by different molecular mechanisms and requires catalytic activity of USP15, but not that of OTUB1, which rather binds to and inhibits the ubiquitin-conjugating activity of the cognate E2 enzyme [176, 178]. In addition, USP15 also promotes TGF- $\beta$ /BMP signaling by opposing monoubiquitylation of R-SMADs, thereby allowing activated R-SMAD-SMAD4 complexes to recognize target promoters [177]. Fourth, DUBs target monoubiquitylated SMAD4 to regulate its interactions. Both, USP9X and USP4 have been shown to catalyze this reaction to promote activated R-SMAD/SMAD4 complex formation, nuclear translocation, and TGF- $\beta$-induced transcriptional activation required for zebrafish development and mESC differentiation (in case of USP4 [97]) or Xenopus development (in case of USP9X [179]).

Thus, as outlined in the above examples, multiple DUBs modulate TGF- $\beta$ /BMP signaling at the receptor or effector level through prevention of degradation or control of protein-protein interactions. In this context, to achieve a certain biological outcome, the same DUB can regulate the pathway at different levels (e.g., USP15 and USP4 promote signaling by targeting the TGF- $\beta$ receptor and the effector SMADs) or multiple DUBs can act on the same target (e.g., USP15 and OTUB1 promote signaling through stabilizing R-SMADs). Future experiments are required to further examine how DUB interplay at these different levels is spatially and temporally regulated to ensure proper TGF- $\beta$ / BMP signaling responses during embryonic development.

\section{Dysregulation of DUBs results in developmental diseases}

Extensive studies over the last decades have established that dysregulation of DUBs leads to human diseases, in particular cancer, neurodegeneration, and inflammation $[1,25-$ $28,45,46]$. In addition, mutations in DUBs frequently cause severe developmental disorders (summarized in Table 1). In general, these disorders are characterized by early-onset neurologic deficits and are thought to be caused by loss-offunction mechanisms. In the following, we will discuss select examples of DUBs that have been directly linked to monogenic developmental disorders and the proposed mechanisms of pathogenesis.

\section{Microcephaly-capillary malformation (MIC-CAP) syndrome (MIM:614261) caused by mutations in STAMBP/AMSH}

Recessive loss-of-function mutations in $S T A M B P$, also known as AMSH, causes MIC-CAP syndrome [146]. These patients have severe microcephaly with progressive cortical atrophy, intractable epilepsy, profound developmental delay, and multiple small capillary malformations on the skin. A variety of disease-causing mutations have been identified including frameshift, nonsense, splicing, and missense mutations, implicating loss-of-function as a mechanism of disease [146, 180-183]. Indeed, Amsh-deficient mice exhibit defects in cortical development similar to those in patients [39]. AMSH is a DUB that, through its K63-specific ubiquitin cleavage activity [184], controls the fate of endosomal cargos that undergo ubiquitin-dependent sorting into degradation or recycling compartments by the ESCRT pathway $[65,185]$. The reported disease-causing missense mutations in AMSH are located either in the catalytic domain reducing its K63-cleavage activity [186] or in the MIT domain potentially affecting binding to components of the ESCRT pathway [146, 185]. During the pathogenesis of MIC-CAP, dysregulation of endosomal sorting likely interferes with appropriate responses to downregulate RAS/PI3K signaling, ultimately leading to the congenital anomalies observed in patients. In support of this, phenotypes of MIC-CAP syndrome closely resemble those of RASopathies, developmental disorders caused by activating mutations in the RAS-ERK signaling pathway [187]. However, the molecular details of how the loss of AMSH activity results increased RAS/PI3K signaling and the key substrates involved remain to be determined.

\section{Hao-Fountain syndrome (MIM:616863) caused by heterozygous mutations in USP7}

USP7 encodes an essential DUB for which disruption of one allele, whether via heterozygous deletions or nonsense/missense mutations, results in Hao-Foutain syndrome, a developmental disorder with seizures, behavioral abnormalities, hypogonadism, and hypotonia [141, 188]. Surprisingly, the 
molecular origin of this disease was not primarily linked to dysregulation of the many essential functions of USP7 in DNA repair, transcription, immune responses, or viral replication [189, 190], but rather to an aberrant role in cellular protein trafficking [141]. Elegant cell biological and biochemical studies demonstrated that USP7 is a component of the MAGE-L2-TRIM27 complex, a multi-subunit ubiquitin E3 ligase with well-established roles in retromer-dependent endosomal recycling of membrane proteins. MAGE-L2TRIM27 regulates endosomal sorting through conjugation of K63-linked ubiquitin chains to WASH, thereby activating this actin nucleation promoting factor and facilitating endosomal actin assembly [191]. USP7 acts as a rheostat for this reaction by (1) deubiquitylating TRIM27 to protect it from auto-degradation and (2) by deubiquitylating WASH to limit its activity, thus fine-tuning endosomal actin assembly [141]. MAGE-L2 is located within the Prader-Willi imprinting region [192] and was identified as the causative gene in Schaaf-Yang syndrome [193, 194]. These two disorders share many disease manifestations with Hao-Fountain syndrome, further suggesting that the USP7-deficiencyinduced patient phenotypes are caused by aberrant endosomal sorting.

\section{Mental retardation, X-linked 99 (MRX99, MIM:300919, 300968) caused by mutations in USP9X}

Mutations in USP9X, encoding an X-linked DUB, cause syndromic and non-syndromic intellectual disability. Initial studies reported three male individuals with non-syndromic $\mathrm{X}$-linked intellectual disability, all carrying missense variants in USP9X [195]. Consistent with this, brain-specific knockout of $U s p 9 x$ causes aberrant cortical architecture similar to that found in patients [196]. Reijinders et al. showed that heterozygous loss-of-function alleles present in females, as opposed to males, lead to a syndromic form of $\mathrm{X}$-linked intellectual disability associated with characteristic facial features, short stature, cardiac, and structural brain abnormalities [197]. Together with more recent studies, this solidified a spectrum of neurodevelopmental disease in male and females with variable phenotypes, decreased penetrance, and likely variant-specific mechanisms of disease, contributing to the different sex-specific manifestations [198, 199]. USP9X is an essential DUB that, through counteracting mono- and polyubiquitylation of specific substrates, has been implicated in a plethora of cellular processes [200]. Dysregulation of several of these functions have been proposed to lead to the phenotypes observed in patients. First, as described above, USP9X regulates TGF- $\beta$ signaling through deubiquitylating SMAD4 and this pathway is defective in patient fibroblasts [199]. Second,
USP9X has been shown to control centriole duplication and centrosome biogenesis through e.g., deubiquitylating and stabilizing the centriole duplication factor STIL [201-203] as well as cilia assembly through regulating the localization and stability of the ciliogenesis-promoting factor NPHP5 [204]. Mutations in genes regulating these processes (including STIL and ICQB1 encoding for NPHP5) frequently result in primary microcephaly [205, 206] and ciliopathies [207, 208], respectively, with considerable phenotypic overlap with USP9X patients, thus suggesting that aberrant centrosome duplication and cilia assembly could contribute to MRX99. Third, USP9X has been shown to regulate dendritic spine development and maintenance [144]. This occurs through deubiquitylation and stabilization of ankyrin-G, a scaffold protein that links plasma membrane proteins to the actin/ $\beta$-spectrin cytoskeleton and thereby regulates multiple neurobiological processes such as synaptogenesis and synaptic plasticity [209-211]. Variants in $A N K$, encoding for ankyrin-G are associated with neurodevelopmental disorders [212] and USP9X patient mutations were shown to reduce interaction with ankyrin-G, strongly suggesting that abnormal ankyrin-G degradation is a pathogenic mechanism in MRX99. Consistent with this, Usp9X knockout mice exhibit synaptic abnormalities, ankyrin-G aggregates, and hyperactivity [144].

It is interesting to note that TGF- $\beta$ promotes cortical spine development through promoting USP9X-dependent stabilization of ankyrin-G [145] and that TGF- $\beta$ signaling can rely on primary cilia [213]. This raises the intriguing possibility that the aforementioned pathogenic mechanisms may be interconnected and that USP9X orchestrates neurodevelopment by acting on several distinct substrates in different pathways. Future research should focus on such interplay and test the relative contributions of different substrates and functions to the sex-specific MRX99 manifestations.

\section{Intellectual developmental disorder with dysmorphic faces, seizures, and distal limb anomalies (MIM:617452) caused by recessive mutations in OTUD6B}

Bi-allelic loss-of-function of OTUD6B causes global developmental delay, feeding difficulties, structural brain abnormalities, and congenital heart disease [40, 214]. OTUD6B is a poorly characterized OTU DUB with no clearly assigned in vitro deubiquitylation activity or ubiquitin-linkage preference [61]. It has been connected to protein translation [215] and may regulate proteasome stability [40]; however, further mechanistic studies are required to establish whether loss of these or other functions of OTUD6B drive the aberrant differentiation processes observed in $O T U D 6 B$ patients. 
15q13.3 microdeletion syndrome (MIM:612001) caused in part by haploinsufficiency of OTUD7A

OTUD7A, encoding a poorly studied K11-specfic OTU DUB [61], is located in the $15 \mathrm{q} 13.3$ locus, which when deleted causes a wide spectrum of neurodevelopmental and psychiatric disorders [216-219]. 15q13.3 microdeletion syndrome is the most common genetic cause of epilepsy [220]. Recent studies have shown that out of the six proteincoding genes that are typically encompassed in the deletions, OTUD7A is the most likely candidate to cause associated epilepsy. First, studies in mice have shown that OTUD7A controls dendritic branching of cortical neurons [86]. Second, knockout of Otud7a recapitulated neurodevelopmental deficits including abnormal EEGs [87]. Third, an individual with neurodevelopmental phenotypes and epilepsy carrying biallelic OTUD7A missense variants has been reported [221]. These findings highlight an important role in OTUD7A in controlling neurodevelopment; yet, the molecular underpinnings of this regulation, including cellular mechanisms and cognate E3 ligases and substrates, have remained largely unclear. Their identification will have important implications for understanding distinct forms of epilepsy.

\section{Linkage-specific deubiquitylation deficiency- induced embryonic defect (LINKED) syndrome caused by mutations in OTUD5}

Hemizygous missense and deletion variants in OTUD5, encoding an X-linked OTU DUB that prefers cleavage of K48- and K63-linked ubiquitin chains [61, 222-224], have recently been shown to cause a male-specific multiple congenital disorder [41]. Affected patients suffer from a spectrum of central nervous system, craniofacial, cardiac, skeletal, and genitourinary anomalies. OTUD5 has previously been implicated in regulating innate and adaptive immune signaling [224-226]; however, the reported patient phenotypes suggest an additional role of this enzyme during embryonic cell-fate determination. Indeed, knockout of Otud5 is embryonic lethal in mice and OTUD5-depleted hESCs are defective in neuroectodermal differentiation, which can be rescued by reexpression of wild-type OTUD5 [41]. Interestingly, a patient variant that affects K48- but not K63-ubiquitin chain cleavage activity, is not able to rescue the differentiation defects, suggesting that the disease originates from loss of OTUD5's activity towards degradative K48-linked ubiquitin chains. Corroborating this notion, OTUD5 prevents the degradation of multiple chromatin remodelers to coordinate enhancer activation during neuroectodermal differentiation. Amongst these OTUD5 substrates are ARID1A/B, HDAC2, and HCF1, mutations of which underlie different developmental disorders (Coffin-Siris and Cornelia de Lange syndromes [227, 228],
X-linked mental retardation 3 [229]) that exhibit considerable phenotypic overlap with LINKED patients. Thus, this work reveals K48-ubiquitin chain cleavage of functionally related substrates as an essential signaling mode coordinating chromatin remodeling during early human development. Additional experiments are required to determine the molecular details of this regulation in the broader context of embryogenesis.

\section{Conclusion and perspectives}

Since the initial discovery of DUBs almost 40 years ago, numerous studies have provided insights into their structures, substrate/cleavage specificities, and regulatory mechanisms that allow this versatile enzyme family to contribute to diverse cellular processes. In particular, we here highlight principles of how DUBs modulate ubiquitin signaling during embryonic and postnatal development and the emerging roles of their dysregulation in congenital disorders. Despite many recent advances in our understanding of DUBs in these (patho-)physiological processes, many open questions remain. First, for more than half of the human DUBs, substrates and linkage specificities have remained unclear [26]. Moreover, as several DUBs are relatively large proteins challenging to produce in bacteria, many biochemical activities have been determined with truncation variants, which could lack important specificity determinants encoded in the full-length protein. Similarly, as detailed in this review, PTMs and co-factors have been shown to regulate DUB activity and linkage-specificities in cells and those contributions are not captured during in vitro activity assays using bacterial proteins. Therefore, characterizing DUB mechanisms and specificities by in vitro and cell-based assays, particularly focusing on fulllength proteins, will be important to further define physiological roles of DUBs and elucidate their role in disease. Second, as alluded to throughout this review, it is often unclear how the intricate regulatory mechanisms that can regulate DUB localization, activity, and substrate recruitment in vitro are implemented to ensure faithful embryonic and postnatal development in vivo. Third, while mutations in $~ 10$ DUBs have been convincingly demonstrated to cause developmental disease (Fig. 4), the underlying mechanisms, E3 ligases, and/or substrates are often illdefined (e.g., OTUD6B and OTUD7A). Fourth, knockout or knockdown of tens of DUBs has been shown to be lethal or to cause severe defects during embryogenesis of model organisms such as zebrafish and mice [43, 44]. In many cases, these DUBs have not yet been associated with congenital disorders and/or their precise functions and underlying mechanisms in early human development are not known (e.g., OTUD4, USP25). 


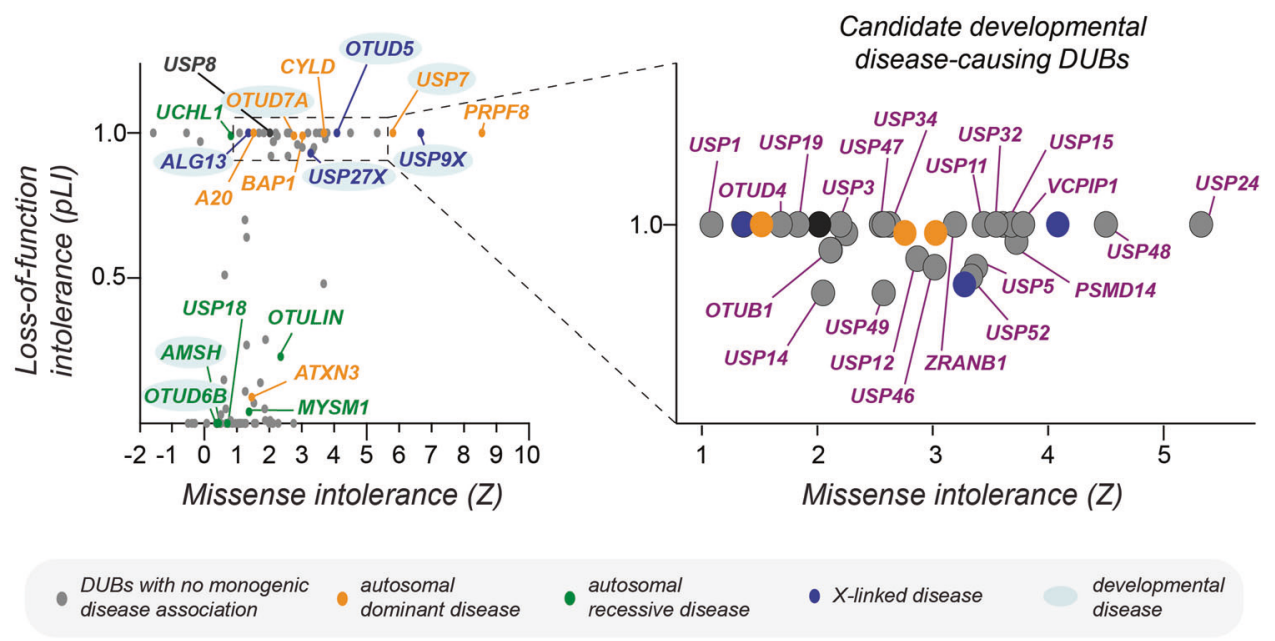

Fig. 4 Many DUBs are intolerant to genomic variation in humans and are likely to cause developmental disease when mutated. Graph depicting a plot of missense (Z) and loss-of-function intolerance (pLI) scores of all human DUBs (as determined using gnomAD [233]). Highlighted in color are DUBs whose mutations have been demonstrated to cause monogenic diseases that are inherited in an autosomal dominant manner (orange), autosomal recessive manner (green), or Xlinked dominant/recessive manner (blue). Mutations in USP8 (highlighted in black) cause corticotroph adenomas and Cushing's disease in the somatic state. Note that DUBs associated with autosomal dominant and $\mathrm{X}$-linked disease are constrained in their genomic variation within the healthy human population $(\mathrm{pLI} \approx 1, Z$-score $>1$ ). Many other DUBs, previously not linked to monogenic diseases, are also highly intolerant to missense and loss-of-function mutations and thus likely cause embryonic lethality or developmental disease when mutated. The strongest of these candidates are highlighted in violet in the zoomed-in panel of the plot on the right.
With the rapid increase in databases of exome and genome sequences from healthy individuals, it has now become possible to quantify the tolerance of genes to loss-offunction and missense mutations in control populations. [230-233] Genes that are highly restricted in such variation are likely to be essential and, when mutated, either result in embryonic lethality or developmental disease. As recently demonstrated for OTUD5 and LINKED syndrome [41], such genomic constraint metrics can be used to prioritize candidate disease variants and, combined with mechanistic studies, facilitate the discovery of novel developmental pathways. Intriguingly, there are many DUBs, not yet associated with congenital disorders, but that are likely to be disease-causing based on how constrained they are from mutations in the healthy population (highlighted in violet in Fig. 4). We propose that systematic search for missense variants in these genes in patients with undiagnosed diseases, will likely allow identification of novel developmental disorders and may yield variants that can be used to dissect functions and mechanisms of these DUBs during embryogenesis. Even if such patients are not readily identified, these tools provide clues about enzymes important for human health to prioritize for mechanistic studies. Such genomic constraint-based genotype-first approaches would be especially interesting for poorly characterized DUBs such as USP24, USP48, and USP32. It would be equally attractive to apply this methodology to the linkage-specific
OTU DUBs OTUD4, OTUB1, VCPIP, and ZRANB1 [61] to uncover potentially novel roles of particular ubiquitin chain types during early development. Finally, such methodologies could provide important mechanistic insights to help improve disease diagnosis and patient management and, given the growing ability to target the activity of specific DUBs with small molecules [26, 45, 234], potentially open new avenues for therapeutic intervention to ameliorate disease symptoms.

Acknowledgements We apologize to all scientists whose work could not be discussed within the space confines of this review. We thank members of our lab for continuous help and discussions, and we are grateful to Drs Nadine Samara and Shireen Sarraf for comments on this manuscript. MAB and AW are funded by the intramural program of the NIDCR and DBB by the intramural program of NHGRI.

Author contributions MAB and DBB helped conceptualize and formulate the design of the article, interpreted relevant literature, wrote the original draft of the manuscript. AW conceptualized and formulated the design of the article, interpreted relevant literature, edited the draft of the manuscript, designed figures, and acquired funding.

\section{Compliance with ethical standards}

Conflict of interest The authors declare that they have no conflict of interest.

Publisher's note Springer Nature remains neutral with regard to jurisdictional claims in published maps and institutional affiliations. 
Open Access This article is licensed under a Creative Commons Attribution 4.0 International License, which permits use, sharing, adaptation, distribution and reproduction in any medium or format, as long as you give appropriate credit to the original author(s) and the source, provide a link to the Creative Commons license, and indicate if changes were made. The images or other third party material in this article are included in the article's Creative Commons license, unless indicated otherwise in a credit line to the material. If material is not included in the article's Creative Commons license and your intended use is not permitted by statutory regulation or exceeds the permitted use, you will need to obtain permission directly from the copyright holder. To view a copy of this license, visit http://creativecommons. org/licenses/by/4.0/.

\section{References}

1. Oh E, Akopian D, Rape M. Principles of ubiquitin-dependent signaling. Annu Rev Cell Dev Biol. 2018;34:137-62.

2. Strikoudis A, Guillamot M, Aifantis I. Regulation of stem cell function by protein ubiquitylation. EMBO Rep. 2014;15:365-82.

3. Werner A, Manford AG, Rape M. Ubiquitin-dependent regulation of stem cell biology. Trends Cell Biol. 2017;27:568-79.

4. Komander D, Rape M. The ubiquitin code. Annu Rev Biochem. 2012;81:203-29.

5. Dikic I, Wakatsuki S, Walters KJ. Ubiquitin-binding domainsfrom structures to functions. Nat Rev Mol Cell Biol. 2009;10:659-71.

6. Husnjak K, Dikic I. Ubiquitin-binding proteins: decoders of ubiquitin-mediated cellular functions. Annu Rev Biochem. 2012;81:291-322.

7. Haakonsen DL, Rape M. Branching out: improved signaling by heterotypic ubiquitin chains. Trends Cell Biol. 2019;29:704-16.

8. Di Fiore PP, Polo S, Hofmann K. When ubiquitin meets ubiquitin receptors: a signalling connection. Nat Rev Mol Cell Biol. 2003;4:491-7.

9. Haglund K, Dikic I. Ubiquitylation and cell signaling. EMBO J. 2005;24:3353-9.

10. Morgan MT, Wolberger C. Recognition of ubiquitinated nucleosomes. Curr Opin Struct Biol. 2017;42:75-82.

11. Werner A, Iwasaki S, McGourty CA, Medina-Ruiz S, Teerikorpi $\mathrm{N}$, Fedrigo I, et al. Cell-fate determination by ubiquitindependent regulation of translation. Nature. 2015;525:523-7.

12. Chau V, Tobias JW, Bachmair A, Marriott D, Ecker DJ, Gonda DK, et al. A multiubiquitin chain is confined to specific lysine in a targeted short-lived protein. Science. 1989;243:1576-83.

13. Jin L, Williamson A, Banerjee S, Philipp I, Rape M. Mechanism of ubiquitin-chain formation by the human anaphase-promoting complex. Cell. 2008;133:653-65.

14. Tokunaga F, Sakata S, Saeki Y, Satomi Y, Kirisako T, Kamei K, et al. Involvement of linear polyubiquitylation of NEMO in NFkappaB activation. Nat Cell Biol. 2009;11:123-32.

15. Wang C, Deng L, Hong M, Akkaraju GR, Inoue J, Chen ZJ. TAK1 is a ubiquitin-dependent kinase of MKK and IKK. Nature. 2001;412:346-51.

16. Doil C, Mailand N, Bekker-Jensen S, Menard P, Larsen DH, Pepperkok R, et al. RNF168 binds and amplifies ubiquitin conjugates on damaged chromosomes to allow accumulation of repair proteins. Cell. 2009;136:435-46.

17. Hoege C, Pfander B, Moldovan GL, Pyrowolakis G, Jentsch S. RAD6-dependent DNA repair is linked to modification of PCNA by ubiquitin and SUMO. Nature. 2002;419:135-41.

18. Stewart GS, Panier S, Townsend K, Al-Hakim AK, Kolas NK, Miller ES, et al. The RIDDLE syndrome protein mediates a ubiquitin-dependent signaling cascade at sites of DNA damage. Cell. 2009;136:420-34.

19. Grumati P, Dikic I. Ubiquitin signaling and autophagy. J Biol Chem. 2018;293:5404-13.

20. Kim W, Bennett EJ, Huttlin EL, Guo A, Li J, Possemato A, et al. Systematic and quantitative assessment of the ubiquitin-modified proteome. Mol Cell. 2011;44:325-40.

21. Pickart CM. Mechanisms underlying ubiquitination. Annu Rev Biochem. 2001;70:503-33.

22. Komander D, Clague MJ, Urbe S. Breaking the chains: structure and function of the deubiquitinases. Nat Rev Mol Cell Biol. 2009;10:550-63.

23. Newton K, Matsumoto ML, Wertz IE, Kirkpatrick DS, Lill JR, Tan $\mathrm{J}$, et al. Ubiquitin chain editing revealed by polyubiquitin linkage-specific antibodies. Cell. 2008;134:668-78.

24. Ronau JA, Beckmann JF, Hochstrasser M. Substrate specificity of the ubiquitin and Ubl proteases. Cell Res. 2016;26:441-56.

25. Bonacci T, Emanuele MJ. Dissenting degradation: deubiquitinases in cell cycle and cancer. Semin Cancer Biol. 2020;67:14558.

26. Clague MJ, Urbe S, Komander D. Breaking the chains: deubiquitylating enzyme specificity begets function. Nat Rev Mol Cell Biol. 2019;20:338-52.

27. Heideker J, Wertz IE. DUBs, the regulation of cell identity and disease. Biochem J. 2015;465:1-26.

28. Leznicki P, Kulathu Y. Mechanisms of regulation and diversification of deubiquitylating enzyme function. J Cell Sci. 2017;130:1997-2006.

29. Gomez-Diaz C, Ikeda F. Roles of ubiquitin in autophagy and cell death. Semin Cell Dev Biol. 2019;93:125-35.

30. Vucic D, Dixit VM, Wertz IE. Ubiquitylation in apoptosis: a post-translational modification at the edge of life and death. Nat Rev Mol Cell Biol. 2011;12:439-52.

31. Kon N, Kobayashi Y, Li M, Brooks CL, Ludwig T, Gu W. Inactivation of HAUSP in vivo modulates p53 function. Oncogene. 2010;29:1270-9.

32. Niendorf S, Oksche A, Kisser A, Lohler J, Prinz M, Schorle H, et al. Essential role of ubiquitin-specific protease 8 for receptor tyrosine kinase stability and endocytic trafficking in vivo. Mol Cell Biol. 2007;27:5029-39.

33. Naik E, Webster JD, DeVoss J, Liu J, Suriben R, Dixit VM. Regulation of proximal $\mathrm{T}$ cell receptor signaling and tolerance induction by deubiquitinase Usp9X. J Exp Med. 2014;211:1947-55.

34. Pantaleon M, Kanai-Azuma M, Mattick JS, Kaibuchi K, Kaye PL, Wood SA. FAM deubiquitylating enzyme is essential for preimplantation mouse embryo development. Mech Dev. 2001;109:151-60.

35. Yang W, Lee YH, Jones AE, Woolnough JL, Zhou D, Dai Q, et al. The histone $\mathrm{H} 2 \mathrm{~A}$ deubiquitinase Usp16 regulates embryonic stem cell gene expression and lineage commitment. Nat Commun. 2014;5:3818.

36. Lin Z, Yang H, Kong Q, Li J, Lee SM, Gao B, et al. USP22 antagonizes p53 transcriptional activation by deubiquitinating Sirt1 to suppress cell apoptosis and is required for mouse embryonic development. Mol Cell. 2012;46:484-94.

37. Dey A, Seshasayee D, Noubade R, French DM, Liu J, Chaurushiya MS, et al. Loss of the tumor suppressor BAP1 causes myeloid transformation. Science. 2012;337:1541-6.

38. Pasupala N, Morrow ME, Que LT, Malynn BA, Ma A, Wolberger C. OTUB1 non-catalytically stabilizes the E2 ubiquitinconjugating enzyme UBE2E1 by preventing its autoubiquitination. J Biol Chem. 2018;293:18285-95.

39. Ishii N, Owada Y, Yamada M, Miura S, Murata K, Asao H, et al. Loss of neurons in the hippocampus and cerebral cortex of AMSH-deficient mice. Mol Cell Biol. 2001;21:8626-37. 
40. Santiago-Sim T, Burrage LC, Ebstein F, Tokita MJ, Miller M, Bi $\mathrm{W}$, et al. Biallelic variants in OTUD6B cause an intellectual disability syndrome associated with seizures and dysmorphic features. Am J Hum Genet. 2017;100:676-88.

41. Beck DB, Basar MA, Asmar AJ, Thompson J, Oda H, Uehara DT, et al. Regulation of human development by ubiquitin chain editing of chromatin remodelers. Sci. Adv. 2021. In Press.

42. Cox BJ, Vollmer M, Tamplin O, Lu M, Biechele S, Gertsenstein $\mathrm{M}$, et al. Phenotypic annotation of the mouse $\mathrm{X}$ chromosome. Genome Res. 2010;20:1154-64.

43. Cheng J, Guo J, North BJ, Wang B, Cui CP, Li H, et al. Functional analysis of deubiquitylating enzymes in tumorigenesis and development. Biochim Biophys Acta Rev Cancer. 2019;1872:188312.

44. Tse WK, Eisenhaber B, Ho SH, Ng Q, Eisenhaber F, Jiang YJ. Genome-wide loss-of-function analysis of deubiquitylating enzymes for zebrafish development. BMC Genomics. 2009; 10:637.

45. Harrigan JA, Jacq X, Martin NM, Jackson SP. Deubiquitylating enzymes and drug discovery: emerging opportunities. Nat Rev Drug Discov. 2018;17:57-78.

46. Rape M. Ubiquitylation at the crossroads of development and disease. Nat Rev Mol Cell Biol. 2018;19:59-70.

47. Beck DB, Aksentijevich I. Biochemistry of autoinflammatory diseases: catalyzing monogenic disease. Front Immunol. 2019; 10:101.

48. Hershko A, Ciechanover A, Heller H, Haas AL, Rose IA. Proposed role of ATP in protein breakdown: conjugation of protein with multiple chains of the polypeptide of ATP-dependent proteolysis. Proc Natl Acad Sci USA. 1980;77:1783-6.

49. Pickart CM, Rose IA. Ubiquitin carboxyl-terminal hydrolase acts on ubiquitin carboxyl-terminal amides. J Biol Chem. 1985;260: 7903-10.

50. Pickart CM, Rose IA. Mechanism of ubiquitin carboxyl-terminal hydrolase. Borohydride and hydroxylamine inactivate in the presence of ubiquitin. J Biol Chem. 1986;261:10210-7.

51. Abdul Rehman SA, Kristariyanto YA, Choi SY, Nkosi PJ, Weidlich S, Labib K, et al. MINDY-1 is a member of an evolutionarily conserved and structurally distinct new family of deubiquitinating enzymes. Mol Cell. 2016;63:146-55.

52. Haahr P, Borgermann N, Guo X, Typas D, Achuthankutty D, Hoffmann S, et al. ZUFSP deubiquitylates K63-linked polyubiquitin chains to promote genome stability. Mol Cell. 2018;70:165-74 e166.

53. Hermanns T, Pichlo C, Woiwode I, Klopffleisch K, Witting KF, Ovaa $\mathrm{H}$, et al. A family of unconventional deubiquitinases with modular chain specificity determinants. Nat Commun. 2018;9:799.

54. Hewings DS, Heideker J, Ma TP, AhYoung AP, El Oualid F, Amore A, et al. Reactive-site-centric chemoproteomics identifies a distinct class of deubiquitinase enzymes. Nat Commun. 2018;9:1162.

55. Kwasna D, Abdul Rehman SA, Natarajan J, Matthews S, Madden R, De Cesare V, et al. Discovery and characterization of ZUFSP/ZUP1, a distinct deubiquitinase class important for genome stability. Mol Cell. 2018;70:150-64 e156.

56. Walden M, Masandi SK, Pawlowski K, Zeqiraj E. Pseudo-DUBs as allosteric activators and molecular scaffolds of protein complexes. Biochem Soc Trans. 2018;46:453-66.

57. Komander D. Mechanism, specificity and structure of the deubiquitinases. Subcell Biochem. 2010;54:69-87.

58. Reyes-Turcu FE, Ventii KH, Wilkinson KD. Regulation and cellular roles of ubiquitin-specific deubiquitinating enzymes. Annu Rev Biochem. 2009;78:363-97.

59. Mevissen TET, Komander D. Mechanisms of deubiquitinase specificity and regulation. Annu Rev Biochem. 2017;86:159-92.
60. Wolberger C. Mechanisms for regulating deubiquitinating enzymes. Protein Sci. 2014;23:344-53.

61. Mevissen TE, Hospenthal MK, Geurink PP, Elliott PR, Akutsu $\mathrm{M}$, Arnaudo N, et al. OTU deubiquitinases reveal mechanisms of linkage specificity and enable ubiquitin chain restriction analysis. Cell. 2013;154:169-84.

62. Kristariyanto YA, Abdul Rehman SA, Weidlich S, Knebel A, Kulathu Y. A single MIU motif of MINDY-1 recognizes K48linked polyubiquitin chains. EMBO Rep. 2017;18:392-402.

63. Reyes-Turcu FE, Horton JR, Mullally JE, Heroux A, Cheng X, Wilkinson KD. The ubiquitin binding domain $\mathrm{ZnF}$ UBP recognizes the C-terminal diglycine motif of unanchored ubiquitin. Cell. 2006;124:1197-208.

64. Cooper EM, Boeke JD, Cohen RE. Specificity of the BRISC deubiquitinating enzyme is not due to selective binding to Lys63-linked polyubiquitin. J Biol Chem. 2010;285:10344-52.

65. McCullough J, Row PE, Lorenzo O, Doherty M, Beynon R, Clague MJ, et al. Activation of the endosome-associated ubiquitin isopeptidase AMSH by STAM, a component of the multivesicular body-sorting machinery. Curr Biol. 2006;16:160-5.

66. Sato Y, Yoshikawa A, Yamagata A, Mimura H, Yamashita M, Ookata K, et al. Structural basis for specific cleavage of Lys 63linked polyubiquitin chains. Nature. 2008;455:358-62.

67. Cunningham CN, Baughman JM, Phu L, Tea JS, Yu C, Coons $\mathrm{M}$, et al. USP30 and parkin homeostatically regulate atypical ubiquitin chains on mitochondria. Nat Cell Biol. 2015;17:160-9.

68. Gersch M, Gladkova C, Schubert AF, Michel MA, Maslen S, Komander D. Mechanism and regulation of the Lys6-selective deubiquitinase USP30. Nat Struct Mol Biol. 2017;24:920-30.

69. Sato Y, Okatsu K, Saeki Y, Yamano K, Matsuda N, Kaiho A, et al. Structural basis for specific cleavage of Lys6-linked polyubiquitin chains by USP30. Nat Struct Mol Biol. 2017;24:911-9.

70. Komander D, Reyes-Turcu F, Licchesi JD, Odenwaelder P, Wilkinson KD, Barford D. Molecular discrimination of structurally equivalent Lys 63-linked and linear polyubiquitin chains. EMBO Rep. 2009;10:466-73.

71. Sato Y, Goto E, Shibata Y, Kubota Y, Yamagata A, Goto-Ito S, et al. Structures of CYLD USP with Met1- or Lys63-linked diubiquitin reveal mechanisms for dual specificity. Nat Struct Mol Biol. 2015;22:222-9.

72. Faesen AC, Luna-Vargas MP, Geurink PP, Clerici M, Merkx R, van Dijk WJ, et al. The differential modulation of USP activity by internal regulatory domains, interactors and eight ubiquitin chain types. Chem Biol. 2011;18:1550-61.

73. Deshaies RJ, Joazeiro CA. RING domain E3 ubiquitin ligases. Annu Rev Biochem. 2009;78:399-434.

74. Asmar AJ, Beck DB, Werner A. Control of craniofacial and brain development by Cullin3-RING ubiquitin ligases: lessons from human disease genetics. Exp Cell Res. 2020;396:112300.

75. Sahtoe DD, Sixma TK. Layers of DUB regulation. Trends Biochem Sci. 2015;40:456-67.

76. Lee MJ, Yaffe MB. Protein regulation in signal transduction. Cold Spring Harb Perspect Biol. 2016;7:a005918.

77. Clague MJ, Barsukov I, Coulson JM, Liu H, Rigden DJ, Urbe S. Deubiquitylases from genes to organism. Physiol Rev. 2013;93: 1289-315.

78. Clague MJ, Heride $\mathrm{C}$, Urbe $\mathrm{S}$. The demographics of the ubiquitin system. Trends Cell Biol. 2015;25:417-26.

79. Fuchs G, Shema E, Vesterman R, Kotler E, Wolchinsky Z, Wilder S, et al. RNF20 and USP44 regulate stem cell differentiation by modulating H2B monoubiquitylation. Mol Cell. 2012;46:662-73.

80. Boyer LA, Lee TI, Cole MF, Johnstone SE, Levine SS, Zucker $\mathrm{JP}$, et al. Core transcriptional regulatory circuitry in human embryonic stem cells. Cell. 2005;122:947-56. 
81. Sussman RT, Stanek TJ, Esteso P, Gearhart JD, Knudsen KE, McMahon SB. The epigenetic modifier ubiquitin-specific protease 22 (USP22) regulates embryonic stem cell differentiation via transcriptional repression of sex-determining region Y-box 2 (SOX2). J Biol Chem. 2013;288:24234-46.

82. Kapushesky M, Adamusiak T, Burdett T, Culhane A, Farne A, Filippov A, et al. Gene Expression Atlas update-a value-added database of microarray and sequencing-based functional genomics experiments. Nucleic Acids Res. 2012;40:D1077-1081.

83. Lowe J, McDermott H, Landon M, Mayer RJ, Wilkinson KD. Ubiquitin carboxyl-terminal hydrolase (PGP 9.5) is selectively present in ubiquitinated inclusion bodies characteristic of human neurodegenerative diseases. J Pathol. 1990;161:153-60.

84. Burnett B, Li F, Pittman RN. The polyglutamine neurodegenerative protein ataxin-3 binds polyubiquitylated proteins and has ubiquitin protease activity. Hum Mol Genet. 2003;12:3195-205.

85. Kawaguchi Y, Okamoto T, Taniwaki M, Aizawa M, Inoue M, Katayama S, et al. CAG expansions in a novel gene for Machado-Joseph disease at chromosome 14q32.1. Nat Genet. 1994;8:221-8.

86. Uddin M, Unda BK, Kwan V, Holzapfel NT, White SH, Chalil $\mathrm{L}$, et al. OTUD7A regulates neurodevelopmental phenotypes in the 15q13.3 microdeletion syndrome. Am J Hum Genet. 2018;102:278-95.

87. Yin J, Chen W, Chao ES, Soriano S, Wang L, Wang W, et al. Otud7a knockout mice recapitulate many neurological features of $15 \mathrm{q} 13.3$ microdeletion syndrome. Am J Hum Genet. 2018;102:296-308.

88. Bilguvar K, Tyagi NK, Ozkara C, Tuysuz B, Bakircioglu M, Choi M, et al. Recessive loss of function of the neuronal ubiquitin hydrolase UCHL1 leads to early-onset progressive neurodegeneration. Proc Natl Acad Sci USA. 2013;110:3489-94.

89. Gong B, Cao Z, Zheng P, Vitolo OV, Liu S, Staniszewski A, et al. Ubiquitin hydrolase Uch-L1 rescues beta-amyloid-induced decreases in synaptic function and contextual memory. Cell. 2006;126:775-88.

90. Leroy E, Boyer R, Auburger G, Leube B, Ulm G, Mezey E, et al. The ubiquitin pathway in Parkinson's disease. Nature. 1998;395: 451-2.

91. Legarda D, Justus SJ, Ang RL, Rikhi N, Li W, Moran TM, et al. CYLD proteolysis protects macrophages from TNF-mediated auto-necroptosis induced by LPS and licensed by type I IFN. Cell Rep. 2016;15:2449-61.

92. O'Donnell MA, Perez-Jimenez E, Oberst A, Ng A, Massoumi R, Xavier R, et al. Caspase 8 inhibits programmed necrosis by processing CYLD. Nat Cell Biol. 2011;13:1437-42.

93. Coornaert B, Baens M, Heyninck K, Bekaert T, Haegman M, Staal J, et al. T cell antigen receptor stimulation induces MALT1 paracaspase-mediated cleavage of the NF-kappaB inhibitor A20. Nat Immunol. 2008;9:263-71.

94. Huang TT, Nijman SM, Mirchandani KD, Galardy PJ, Cohn MA, Haas W, et al. Regulation of monoubiquitinated PCNA by DUB autocleavage. Nat Cell Biol. 2006;8:339-47.

95. Piatkov KI, Colnaghi L, Bekes M, Varshavsky A, Huang TT. The auto-generated fragment of the Usp1 deubiquitylase is a physiological substrate of the N-end rule pathway. Mol Cell. 2012;48:926-33.

96. Zhang L, Zhou F, Drabsch Y, Gao R, Snaar-Jagalska BE, Mickanin C, et al. USP4 is regulated by AKT phosphorylation and directly deubiquitylates TGF-beta type I receptor. Nat Cell Biol. 2012;14:717-26.

97. Zhou F, Xie F, Jin K, Zhang Z, Clerici M, Gao R, et al. USP4 inhibits SMAD4 monoubiquitination and promotes activin and BMP signaling. EMBO J. 2017;36:1623-39.

98. Bauer NC, Doetsch PW, Corbett AH. Mechanisms regulating protein localization. Traffic. 2015;16:1039-61.
99. Urbe S, Liu H, Hayes SD, Heride C, Rigden DJ, Clague MJ. Systematic survey of deubiquitinase localization identifies USP21 as a regulator of centrosome- and microtubule-associated functions. Mol Biol Cell. 2012;23:1095-103.

100. Hassink GC, Zhao B, Sompallae R, Altun M, Gastaldello S, Zinin NV, et al. The ER-resident ubiquitin-specific protease 19 participates in the UPR and rescues ERAD substrates. EMBO Rep. 2009;10:755-61.

101. Lee JG, Takahama S, Zhang G, Tomarev SI, Ye Y. Unconventional secretion of misfolded proteins promotes adaptation to proteasome dysfunction in mammalian cells. Nat Cell Biol. 2016;18:765-76.

102. Thorne C, Eccles RL, Coulson JM, Urbe S, Clague MJ. Isoformspecific localization of the deubiquitinase USP33 to the Golgi apparatus. Traffic. 2011;12:1563-74.

103. Leznicki P, Natarajan J, Bader G, Spevak W, Schlattl A, Abdul Rehman SA, et al. Expansion of DUB functionality generated by alternative isoforms - USP35, a case study. J Cell Sci. 2018;131: jes212753.

104. Herhaus L, Perez-Oliva AB, Cozza G, Gourlay R, Weidlich S, Campbell DG, et al. Casein kinase 2 (CK2) phosphorylates the deubiquitylase OTUB1 at Ser16 to trigger its nuclear localization. Sci Signal. 2015;8:ra35.

105. Mashtalir N, Daou S, Barbour H, Sen NN, Gagnon J, HammondMartel I, et al. Autodeubiquitination protects the tumor suppressor BAP1 from cytoplasmic sequestration mediated by the atypical ubiquitin ligase UBE2O. Mol Cell. 2014;54:392-406.

106. Lan X, Atanassov BS, Li W, Zhang Y, Florens L, Mohan RD, et al. USP44 is an integral component of N-CoR that contributes to gene repression by deubiquitinating histone H2B. Cell Rep. 2016;17:2382-93.

107. Atanassov BS, Mohan RD, Lan X, Kuang X, Lu Y, Lin K, et al. ATXN7L3 and ENY2 coordinate activity of multiple H2B deubiquitinases important for cellular proliferation and tumor growth. Mol Cell. 2016;62:558-71.

108. Kolovos P, Nishimura K, Sankar A, Sidoli S, Cloos PA, Helin K, et al. PR-DUB maintains the expression of critical genes through FOXK1/2- and ASXL1/2/3-dependent recruitment to chromatin and H2AK119ub1 deubiquitination. Genome Res. 2020;30: 1119-30.

109. Campagne A, Lee MK, Zielinski D, Michaud A, Le Corre S, Dingli $\mathrm{F}$, et al. BAP1 complex promotes transcription by opposing PRC1-mediated H2A ubiquitylation. Nat Commun. 2019;10:348.

110. Wei X, Guo J, Li Q, Jia Q, Jing Q, Li Y, et al. Bach1 regulates self-renewal and impedes mesendodermal differentiation of human embryonic stem cells. Sci Adv. 2019;5:eaau7887.

111. Scheuermann JC, de Ayala Alonso AG, Oktaba K, Ly-Hartig N, McGinty RK, Fraterman S, et al. Histone H2A deubiquitinase activity of the Polycomb repressive complex PR-DUB. Nature. 2010;465:243-7.

112. Daou S, Hammond-Martel I, Mashtalir N, Barbour H, Gagnon J, Iannantuono NV, et al. The BAP1/ASXL2 histone H2A deubiquitinase complex regulates cell proliferation and is disrupted in cancer. J Biol Chem. 2015;290:28643-63.

113. Sahtoe DD, van Dijk WJ, Ekkebus R, Ovaa H, Sixma TK. BAP1/ASXL1 recruitment and activation for $\mathrm{H} 2 \mathrm{~A}$ deubiquitination. Nat Commun. 2016;7:10292.

114. Daou S, Barbour H, Ahmed O, Masclef L, Baril C, Sen Nkwe N, et al. Monoubiquitination of ASXLs controls the deubiquitinase activity of the tumor suppressor BAP1. Nat Commun. 2018;9:4385.

115. Faesen AC, Dirac AM, Shanmugham A, Ovaa H, Perrakis A, Sixma TK. Mechanism of USP7/HAUSP activation by its Cterminal ubiquitin-like domain and allosteric regulation by GMPsynthetase. Mol Cell. 2011;44:147-59. 
116. Kim RQ, Geurink PP, Mulder MPC, Fish A, Ekkebus R, El Oualid F, et al. Kinetic analysis of multistep USP7 mechanism shows critical role for target protein in activity. Nat Commun. 2019;10:231.

117. van der Knaap JA, Kumar BR, Moshkin YM, Langenberg K, Krijgsveld J, Heck AJ, et al. GMP synthetase stimulates histone H2B deubiquitylation by the epigenetic silencer USP7. Mol Cell. 2005;17:695-707.

118. Cohn MA, Kee Y, Haas W, Gygi SP, D'Andrea AD. UAF1 is a subunit of multiple deubiquitinating enzyme complexes. J Biol Chem. 2009;284:5343-51.

119. Kee Y, Yang K, Cohn MA, Haas W, Gygi SP, D'Andrea AD. WDR20 regulates activity of the USP12 x UAF1 deubiquitinating enzyme complex. J Biol Chem. 2010;285:11252-7.

120. Li H, Lim KS, Kim H, Hinds TR, Jo U, Mao H, et al. Allosteric activation of ubiquitin-specific proteases by beta-propeller proteins UAF1 and WDR20. Mol Cell. 2016;63:249-60.

121. Williams SA, Maecker HL, French DM, Liu J, Gregg A, Silverstein $\mathrm{LB}$, et al. USP1 deubiquitinates ID proteins to preserve a mesenchymal stem cell program in osteosarcoma. Cell. 2011;146:918-30.

122. Borodovsky A, Kessler BM, Casagrande R, Overkleeft HS, Wilkinson KD, Ploegh HL. A novel active site-directed probe specific for deubiquitylating enzymes reveals proteasome association of USP14. EMBO J. 2001;20:5187-96.

123. Qiu XB, Ouyang SY, Li CJ, Miao S, Wang L, Goldberg AL. hRpn13/ADRM1/GP110 is a novel proteasome subunit that binds the deubiquitinating enzyme, UCH37. EMBO J. 2006;25:5742-53.

124. Worden EJ, Padovani C, Martin A. Structure of the Rpn11-Rpn8 dimer reveals mechanisms of substrate deubiquitination during proteasomal degradation. Nat Struct Mol Biol. 2014;21:220-7.

125. Yao T, Song L, Xu W, DeMartino GN, Florens L, Swanson SK, et al. Proteasome recruitment and activation of the Uch37 deubiquitinating enzyme by Adrm1. Nat Cell Biol. 2006;8:994-1002.

126. Buckley SM, Aranda-Orgilles B, Strikoudis A, Apostolou E, Loizou E, Moran-Crusio K, et al. Regulation of pluripotency and cellular reprogramming by the ubiquitin-proteasome system. Cell Stem Cell. 2012;11:783-98.

127. Kohler A, Zimmerman E, Schneider M, Hurt E, Zheng N. Structural basis for assembly and activation of the heterotetrameric SAGA histone H2B deubiquitinase module. Cell. 2010;141:606-17.

128. Koutelou E, Hirsch CL, Dent SY. Multiple faces of the SAGA complex. Curr Opin Cell Biol. 2010;22:374-82.

129. Samara NL, Datta AB, Berndsen CE, Zhang X, Yao T, Cohen $\mathrm{RE}$, et al. Structural insights into the assembly and function of the SAGA deubiquitinating module. Science. 2010;328:1025-9.

130. Xu D, Liu J, Fu T, Shan B, Qian L, Pan L, et al. USP25 regulates Wnt signaling by controlling the stability of tankyrases. Genes Dev. 2017;31:1024-35.

131. Gersch M, Wagstaff JL, Toms AV, Graves B, Freund SMV, Komander D. Distinct USP25 and USP28 oligomerization states regulate deubiquitinating activity. Mol Cell. 2019;74:436-51 e437.

132. Liu B, Sureda-Gomez M, Zhen Y, Amador V, Reverter D. A quaternary tetramer assembly inhibits the deubiquitinating activity of USP25. Nat Commun. 2018;9:4973.

133. Sauer F, Klemm T, Kollampally RB, Tessmer I, Nair RK, Popov $\mathrm{N}$, et al. Differential oligomerization of the deubiquitinases USP25 and USP28 regulates their activities. Mol Cell. 2019;74:421-35 e410.

134. Sowa ME, Bennett EJ, Gygi SP, Harper JW. Defining the human deubiquitinating enzyme interaction landscape. Cell. 2009;138: 389-403.

135. Nielsen CP, MacGurn JA. Coupling conjugation and deconjugation activities to achieve cellular ubiquitin dynamics. Trends Biochem Sci. 2020;45:427-39.
136. Ahmed N, Zeng M, Sinha I, Polin L, Wei WZ, Rathinam C, et al. The E3 ligase Itch and deubiquitinase Cyld act together to regulate Tak1 and inflammation. Nat Immunol. 2011;12:1176-83.

137. Wertz IE, O'Rourke KM, Zhou H, Eby M, Aravind L, Seshagiri $\mathrm{S}$, et al. De-ubiquitination and ubiquitin ligase domains of A20 downregulate NF-kappaB signalling. Nature. 2004;430:694-9.

138. Nielsen CP, Jernigan KK, Diggins NL, Webb DJ, MacGurn JA. USP9X deubiquitylates DVL2 to regulate WNT pathway specification. Cell Rep. 2019;28:1074-89 e1075.

139. Nusse R, Clevers H. Wnt/beta-catenin signaling, disease, and emerging therapeutic modalities. Cell. 2017;169:985-99.

140. Steinhart Z, Angers S. Wnt signaling in development and tissue homeostasis. Development. 2018;145:dev146589.

141. Hao YH, Fountain MD Jr., Fon Tacer K, Xia F, Bi W, Kang SH, et al. USP7 acts as a molecular rheostat to promote WASHdependent endosomal protein recycling and is mutated in a human neurodevelopmental disorder. Mol Cell. 2015;59:956-69.

142. Greenblatt MB, Shin DY, Oh H, Lee KY, Zhai B, Gygi SP, et al. MEKK2 mediates an alternative beta-catenin pathway that promotes bone formation. Proc Natl Acad Sci USA. 2016;113: E1226-1235.

143. Jin J, Liu J, Chen C, Liu Z, Jiang C, Chu H, et al. The deubiquitinase USP21 maintains the stemness of mouse embryonic stem cells via stabilization of Nanog. Nat Commun. 2016;7:13594.

144. Yoon S, Parnell E, Kasherman M, Forrest MP, Myczek K, Premarathne $\mathrm{S}$, et al. Usp9X controls ankyrin-repeat domain protein homeostasis during dendritic spine development. Neuron. 2020;105:506-21 e507.

145. Yoon S, Parnell E, Penzes P. TGF-beta-induced phosphorylation of Usp9X stabilizes ankyrin-G and regulates dendritic spine development and maintenance. Cell Rep. 2020;31:107685.

146. McDonell LM, Mirzaa GM, Alcantara D, Schwartzentruber J, Carter MT, Lee LJ, et al. Mutations in STAMBP, encoding a deubiquitinating enzyme, cause microcephaly-capillary malformation syndrome. Nat Genet. 2013;45:556-62.

147. Gu H, Shi X, Liu C, Wang C, Sui N, Zhao Y, et al. USP8 maintains embryonic stem cell stemness via deubiquitination of EPG5. Nat Commun. 2019;10:1465.

148. Blackledge NP, Farcas AM, Kondo T, King HW, McGouran JF, Hanssen LLP, et al. Variant PRC1 complex-dependent H2A ubiquitylation drives PRC2 recruitment and Polycomb domain formation. Cell. 2014;157:1445-59.

149. Cao R, Wang L, Wang H, Xia L, Erdjument-Bromage H, Tempst $\mathrm{P}$, et al. Role of histone H3 lysine 27 methylation in Polycombgroup silencing. Science. 2002;298:1039-43.

150. Cooper S, Dienstbier M, Hassan R, Schermelleh L, Sharif J, Blackledge NP, et al. Targeting Polycomb to pericentric heterochromatin in embryonic stem cells reveals a role for H2AK119u1 in PRC2 recruitment. Cell Rep. 2014;7:1456-70.

151. Kalb R, Latwiel S, Baymaz HI, Jansen PW, Muller CW, Vermeulen $\mathrm{M}$, et al. Histone $\mathrm{H} 2 \mathrm{~A}$ monoubiquitination promotes histone $\mathrm{H} 3$ methylation in Polycomb repression. Nat Struct Mol Biol. 2014;21:569-71.

152. Kim J, Hake SB, Roeder RG. The human homolog of yeast BRE1 functions as a transcriptional coactivator through direct activator interactions. Mol Cell. 2005;20:759-70.

153. Pavri R, Zhu B, Li G, Trojer P, Mandal S, Shilatifard A, et al. Histone $\mathrm{H} 2 \mathrm{~B}$ monoubiquitination functions cooperatively with FACT to regulate elongation by RNA polymerase II. Cell. 2006;125:703-17.

154. Adorno M, Sikandar S, Mitra SS, Kuo A, Nicolis Di Robilant B, Haro-Acosta V, et al. Usp16 contributes to somatic stem-cell defects in Down's syndrome. Nature. 2013;501:380-4.

155. Jiang XX, Nguyen Q, Chou Y, Wang T, Nandakumar V, Yates $\mathrm{P}$, et al. Control of B cell development by the histone H2A deubiquitinase MYSM1. Immunity. 2011;35:883-96. 
156. Li P, Yang YM, Sanchez S, Cui DC, Dang RJ, Wang XY, et al. Deubiquitinase MYSM1 is essential for normal bone formation and mesenchymal stem cell differentiation. Sci Rep. 2016;6:22211.

157. Zhu P, Zhou W, Wang J, Puc J, Ohgi KA, Erdjument-Bromage $\mathrm{H}$, et al. A histone $\mathrm{H} 2 \mathrm{~A}$ deubiquitinase complex coordinating histone acetylation and $\mathrm{H} 1$ dissociation in transcriptional regulation. Mol Cell. 2007;27:609-21.

158. Liefke R, Karwacki-Neisius V, Shi Y. EPOP interacts with elongin BC and USP7 to modulate the chromatin landscape. Mol Cell. 2016;64:659-72.

159. Morgan MT, Haj-Yahya M, Ringel AE, Bandi P, Brik A, Wolberger C. Structural basis for histone H2B deubiquitination by the SAGA DUB module. Science. 2016;351:725-8.

160. Gu Y, Jones AE, Yang W, Liu S, Dai Q, Liu Y, et al. The histone $\mathrm{H} 2 \mathrm{~A}$ deubiquitinase Usp16 regulates hematopoiesis and hematopoietic stem cell function. Proc Natl Acad Sci USA. 2016;113: E51-60.

161. Lecona E, Narendra V, Reinberg D. USP7 cooperates with SCML2 to regulate the activity of PRC1. Mol Cell Biol. 2015; 35:1157-68.

162. Ning B, Zhao W, Qian C, Liu P, Li Q, Li W, et al. USP26 functions as a negative regulator of cellular reprogramming by stabilising PRC1 complex components. Nat Commun. 2017;8:349.

163. Huang Z, Wu Q, Guryanova OA, Cheng L, Shou W, Rich JN, et al. Deubiquitylase HAUSP stabilizes REST and promotes maintenance of neural progenitor cells. Nat Cell Biol. 2011;13:142-52.

164. Westbrook TF, Hu G, Ang XL, Mulligan P, Pavlova NN, Liang A, et al. SCFbeta-TRCP controls oncogenic transformation and neural differentiation through REST degradation. Nature. 2008;452:370-4.

165. Nicklas S, Hillje AL, Okawa S, Rudolph IM, Collmann FM, van Wuellen T, et al. A complex of the ubiquitin ligase TRIM32 and the deubiquitinase USP7 balances the level of c-Myc ubiquitination and thereby determines neural stem cell fate specification. Cell Death Differ. 2019;26:728-40.

166. Kim JM, Yang YS, Park KH, Ge X, Xu R, Li N, et al. A RUNX2 stabilization pathway mediates physiologic and pathologic bone formation. Nat Commun. 2020;11:2289.

167. Sanz-Ezquerro JJ, Munsterberg AE, Stricker S. Editorial: signaling pathways in embryonic development. Front Cell Dev Biol. 2017;5:76.

168. Le Bras S, Loyer N, Le, Borgne R. The multiple facets of ubiquitination in the regulation of notch signaling pathway. Traffic. 2011;12:149-61.

169. Clague MJ, Coulson JM, Urbe S. Cellular functions of the DUBs. J Cell Sci. 2012;125:277-86.

170. Herhaus L, Sapkota GP. The emerging roles of deubiquitylating enzymes (DUBs) in the TGFbeta and BMP pathways. Cell Signal. 2014;26:2186-92.

171. Gaarenstroom T, Hill CS. TGF-beta signaling to chromatin: how Smads regulate transcription during self-renewal and differentiation. Semin Cell Dev Biol. 2014;32:107-18.

172. Eichhorn PJ, Rodon L, Gonzalez-Junca A, Dirac A, Gili M, Martinez-Saez E, et al. USP15 stabilizes TGF-beta receptor I and promotes oncogenesis through the activation of TGF-beta signaling in glioblastoma. Nat Med. 2012;18:429-35.

173. Iyengar PV, Jaynes P, Rodon L, Lama D, Law KP, Lim YP, et al. USP15 regulates SMURF2 kinetics through C-lobe mediated deubiquitination. Sci Rep. 2015;5:14733.

174. Kit Leng Lui S, Iyengar PV, Jaynes P, Isa Z, Pang B, Tan TZ, et al. USP26 regulates TGF-beta signaling by deubiquitinating and stabilizing SMAD7. EMBO reports. 2017;18:797-808.

175. Zhao Y, Wang X, Wang Q, Deng Y, Li K, Zhang M, et al. USP2a Supports Metastasis by Tuning TGF-beta Signaling. Cell Rep. 2018;22:2442-54.
176. Herhaus L, Al-Salihi M, Macartney T, Weidlich S, Sapkota GP. OTUB1 enhances TGFbeta signalling by inhibiting the ubiquitylation and degradation of active SMAD2/3. Nat Commun. 2013;4:2519.

177. Inui M, Manfrin A, Mamidi A, Martello G, Morsut L, Soligo S, et al. USP15 is a deubiquitylating enzyme for receptor-activated SMADs. Nat Cell Biol. 2011;13:1368-75.

178. Wiener R, Zhang X, Wang T, Wolberger C. The mechanism of OTUB1-mediated inhibition of ubiquitination. Nature. 2012;483: 618-22.

179. Dupont S, Mamidi A, Cordenonsi M, Montagner M, Zacchigna $\mathrm{L}$, Adorno M, et al. FAM/USP9x, a deubiquitinating enzyme essential for TGFbeta signaling, controls Smad4 monoubiquitination. Cell. 2009;136:123-35.

180. Carter MT, Mirzaa G, McDonell LM, Boycott KM. Microcephaly-capillary malformation syndrome. In: Adam MP, Ardinger HH, Pagon RA, Wallace SE, Bean LJH, Stephens K, et al. editors. Seattle (WA): GeneReviews((R)); 1993.

181. Faqeih EA, Bastaki L, Rosti RO, Spencer EG, Zada AP, Saleh MA, et al. Novel STAMBP mutation and additional findings in an Arabic family. Am J Med Genet A. 2015;167A:805-9.

182. Naseer MI, Sogaty S, Rasool M, Chaudhary AG, Abutalib YA, Walker S, et al. Microcephaly-capillary malformation syndrome: Brothers with a homozygous STAMBP mutation, uncovered by exome sequencing. Am J Med Genet A. 2016;170:3018-22.

183. Wu F, Dai Y, Wang J, Cheng M, Wang Y, Li X, et al. Earlyonset epilepsy and microcephalycapillary malformation syndrome caused by a novel STAMBP mutation in a Chinese boy. Mol Med Rep. 2019;20:5145-51.

184. McCullough J, Clague MJ, Urbe S. AMSH is an endosomeassociated ubiquitin isopeptidase. J Cell Biol. 2004;166:487-92.

185. Clague MJ, Urbe S. Endocytosis: the DUB version. Trends Cell Biol. 2006;16:551-9.

186. Shrestha RK, Ronau JA, Davies CW, Guenette RG, Strieter ER, Paul LN, et al. Insights into the mechanism of deubiquitination by JAMM deubiquitinases from cocrystal structures of the enzyme with the substrate and product. Biochemistry. 2014;53:3199-217.

187. Tidyman WE, Rauen KA. The RASopathies: developmental syndromes of Ras/MAPK pathway dysregulation. Curr Opin Genet Dev. 2009;19:230-6.

188. Tacer KF, Potts PR. Cellular and disease functions of the PraderWilli Syndrome gene MAGEL2. Biochem J. 2017;474:2177-90.

189. Li M, Chen D, Shiloh A, Luo J, Nikolaev AY, Qin J, et al. Deubiquitination of $\mathrm{p} 53$ by HAUSP is an important pathway for p53 stabilization. Nature. 2002;416:648-53.

190. Nicholson B, Suresh, Kumar KG. The multifaceted roles of USP7: new therapeutic opportunities. Cell Biochem Biophys. 2011;60:61-68.

191. Hao YH, Doyle JM, Ramanathan S, Gomez TS, Jia D, Xu M, et al. Regulation of WASH-dependent actin polymerization and protein trafficking by ubiquitination. Cell. 2013;152:1051-64.

192. Chibuk TK, Bischof JM, Wevrick R. A necdin/MAGE-like gene in the chromosome 15 autism susceptibility region: expression, imprinting, and mapping of the human and mouse orthologues. BMC Genet. 2001;2:22.

193. Boccaccio I, Glatt-Deeley H, Watrin F, Roeckel N, Lalande M, Muscatelli F. The human MAGEL2 gene and its mouse homologue are paternally expressed and mapped to the Prader-Willi region. Hum Mol Genet. 1999;8:2497-505.

194. Schaaf CP, Gonzalez-Garay ML, Xia F, Potocki L, Gripp KW, Zhang B, et al. Truncating mutations of MAGEL2 cause PraderWilli phenotypes and autism. Nat Genet. 2013;45:1405-8.

195. Homan CC, Kumar R, Nguyen LS, Haan E, Raymond FL, Abidi $\mathrm{F}$, et al. Mutations in USP9X are associated with $\mathrm{X}$-linked 
intellectual disability and disrupt neuronal cell migration and growth. Am J Hum Genet. 2014;94:470-8.

196. Stegeman S, Jolly LA, Premarathne S, Gecz J, Richards LJ, Mackay-Sim A, et al. Loss of Usp9x disrupts cortical architecture, hippocampal development and TGFbeta-mediated axonogenesis. PLoS One. 2013;8:e68287.

197. Reijnders MR, Zachariadis V, Latour B, Jolly L, Mancini GM, Pfundt R, et al. De novo loss-of-function mutations in USP9X cause a female-specific recognizable syndrome with developmental delay and congenital malformations. Am J Hum Genet. 2016;98:373-81.

198. Au PYB, Huang L, Broley S, Gallagher L, Creede E, Lahey D, et al. Two females with mutations in USP9X highlight the variable expressivity of the intellectual disability syndrome. Eur J Med Genet. 2017;60:359-64.

199. Johnson BV, Kumar R, Oishi S, Alexander S, Kasherman M, Vega MS, et al. Partial loss of USP9X function leads to a male neurodevelopmental and behavioral disorder converging on transforming growth factor beta signaling. Biol Psychiatry. 2020;87:100-12.

200. Murtaza M, Jolly LA, Gecz J, Wood SA. La FAM fatale: USP9X in development and disease. Cell Mol Life Sci. 2015;72: 2075-89.

201. Kodani A, Moyer T, Chen A, Holland A, Walsh CA, Reiter JF. SFI1 promotes centriole duplication by recruiting USP9X to stabilize the microcephaly protein STIL. J Cell Biol. 2019;218:2185-97.

202. Han KJ, Wu Z, Pearson CG, Peng J, Song K, Liu CW. Deubiquitylase USP9X maintains centriolar satellite integrity by stabilizing pericentriolar material 1 protein. J Cell Sci. 2019;132: jes221663.

203. Wang Q, Tang Y, Xu Y, Xu S, Jiang Y, Dong Q, et al. The Xlinked deubiquitinase USP9X is an integral component of centrosome. J Biol Chem. 2017;292:12874-84.

204. Das A, Qian J, Tsang WY. USP9X counteracts differential ubiquitination of NPHP5 by MARCH7 and BBS11 to regulate ciliogenesis. PLoS Genet. 2017;13:e1006791.

205. Jayaraman D, Bae BI, Walsh CA. The genetics of primary microcephaly. Annu Rev Genomics Hum Genet. 2018;19: 177-200.

206. Kumar A, Girimaji SC, Duvvari MR, Blanton SH. Mutations in STIL, encoding a pericentriolar and centrosomal protein, cause primary microcephaly. Am J Hum Genet. 2009;84:286-90.

207. Logan CV, Abdel-Hamed Z, Johnson CA. Molecular genetics and pathogenic mechanisms for the severe ciliopathies: insights into neurodevelopment and pathogenesis of neural tube defects. Mol Neurobiol. 2011;43:12-26.

208. Suciu SK, Caspary T. Cilia, neural development and disease. Semin Cell Dev Biol. 2020. In press.

209. Bennett V, Healy J. Organizing the fluid membrane bilayer: diseases linked to spectrin and ankyrin. Trends Mol Med. 2008;14:28-36.

210. Smith KR, Kopeikina KJ, Fawcett-Patel JM, Leaderbrand K, Gao R, Schurmann B, et al. Psychiatric risk factor ANK3/ ankyrin-G nanodomains regulate the structure and function of glutamatergic synapses. Neuron. 2014;84:399-415.

211. Tseng WC, Jenkins PM, Tanaka M, Mooney R, Bennett V. Giant ankyrin-G stabilizes somatodendritic GABAergic synapses through opposing endocytosis of GABAA receptors. Proc Natl Acad Sci USA. 2015;112:1214-9.

212. Iqbal Z, Vandeweyer G, van der Voet M, Waryah AM, Zahoor MY, Besseling JA, et al. Homozygous and heterozygous disruptions of ANK3: at the crossroads of neurodevelopmental and psychiatric disorders. Hum Mol Genet. 2013;22:1960-70.

213. Christensen ST, Morthorst SK, Mogensen JB, Pedersen LB. Primary cilia and coordination of receptor tyrosine kinase (RTK) and transforming growth factor beta (TGF-beta) signaling. Cold Spring Harb Perspect Biol. 2017;9:a028167.

214. Straniero L, Rimoldi V, Solda G, Bellini M, Biasucci G, Asselta $\mathrm{R}$, et al. First replication of the involvement of OTUD6B in intellectual disability syndrome with seizures and dysmorphic features. Front Genet. 2018;9:464.

215. Sobol A, Askonas C, Alani S, Weber MJ, Ananthanarayanan V, Osipo C, et al. Deubiquitinase OTUD6B isoforms are important regulators of growth and proliferation. Mol Cancer Res. 2017;15:117-27.

216. Ben-Shachar S, Lanpher B, German JR, Qasaymeh M, Potocki L, Nagamani SC, et al. Microdeletion 15q13.3: a locus with incomplete penetrance for autism, mental retardation, and psychiatric disorders. J Med Genet. 2009;46:382-8.

217. Lowther C, Costain G, Stavropoulos DJ, Melvin R, Silversides CK, Andrade DM, et al. Delineating the $15 \mathrm{q} 13.3$ microdeletion phenotype: a case series and comprehensive review of the literature. Genet Med. 2015;17:149-57.

218. Masurel-Paulet A, Andrieux J, Callier P, Cuisset JM, Le Caignec C, Holder M, et al. Delineation of 15q13.3 microdeletions. Clin Genet. 2010;78:149-61.

219. Miller DT, Shen Y, Weiss LA, Korn J, Anselm I, Bridgemohan C, et al. Microdeletion/duplication at 15q13.2q13.3 among individuals with features of autism and other neuropsychiatric disorders. J Med Genet. 2009;46:242-8.

220. Sharp AJ, Mefford HC, Li K, Baker C, Skinner C, Stevenson $\mathrm{RE}$, et al. A recurrent $15 \mathrm{q} 13.3$ microdeletion syndrome associated with mental retardation and seizures. Nat Genet. 2008;40: 322-8.

221. Garret P, Ebstein F, Delplancq G, Dozieres-Puyravel B, Boughalem A, Auvin S, et al. Report of the first patient with a homozygous OTUD7A variant responsible for epileptic encephalopathy and related proteasome dysfunction. Clin Genet. 2020;97:567-75.

222. de Vivo A, Sanchez A, Yegres J, Kim J, Emly S, Kee Y. The OTUD5-UBR5 complex regulates FACT-mediated transcription at damaged chromatin. Nucleic Acids Res. 2019;47:729-46.

223. Huang OW, Ma X, Yin J, Flinders J, Maurer T, Kayagaki N, et al. Phosphorylation-dependent activity of the deubiquitinase DUBA. Nat Struct Mol Biol. 2012;19:171-5.

224. Kayagaki N, Phung Q, Chan S, Chaudhari R, Quan C, O'Rourke $\mathrm{KM}$, et al. DUBA: a deubiquitinase that regulates type I interferon production. Science. 2007;318:1628-32.

225. Rutz S, Kayagaki N, Phung QT, Eidenschenk C, Noubade R, Wang X, et al. Deubiquitinase DUBA is a post-translational brake on interleukin-17 production in T cells. Nature. 2015;518:417-21.

226. Guo Y, Jiang F, Kong L, Wu H, Zhang H, Chen X, et al. OTUD5 promotes innate antiviral and antitumor immunity through deubiquitinating and stabilizing STING. Cell Mol Immunol. 2020. In press.

227. Tsurusaki Y, Okamoto N, Ohashi H, Kosho T, Imai Y, Hibi-Ko $\mathrm{Y}$, et al. Mutations affecting components of the SWI/SNF complex cause Coffin-Siris syndrome. Nat Genet. 2012;44: 376-8.

228. Wagner VF, Hillman PR, Britt AD, Ray JW, Farach LS. A De novo HDAC2 variant in a patient with features consistent with Cornelia de Lange syndrome phenotype. Am J Med Genet A. 2019;179:852-6.

229. Huang L, Jolly LA, Willis-Owen S, Gardner A, Kumar R, Douglas E, et al. A noncoding, regulatory mutation implicates HCFC1 in nonsyndromic intellectual disability. Am J Hum Genet. 2012;91:694-702.

230. Deciphering Developmental Disorders S. Large-scale discovery of novel genetic causes of developmental disorders. Nature. 2015;519:223-8. 
231. Lek M, Karczewski KJ, Minikel EV, Samocha KE, Banks E, Fennell T, et al. Analysis of protein-coding genetic variation in 60,706 humans. Nature. 2016;536:285-91.

232. Martin HC, Jones WD, McIntyre R, Sanchez-Andrade G, Sanderson M, Stephenson JD, et al. Quantifying the contribution of recessive coding variation to developmental disorders. Science. 2018;362:1161-4.

233. Karczewski KJ, Francioli LC, Tiao G, Cummings BB, Alfoldi J, Wang Q, et al. The mutational constraint spectrum quantified from variation in 141,456 humans. Nature. 2020;581:434-43.

234. Wertz IE, Murray JM. Structurally-defined deubiquitinase inhibitors provide opportunities to investigate disease mechanisms. Drug Discov Today Technol. 2019;31:109-23.

235. Wu X, Liu S, Sagum C, Chen J, Singh R, Chaturvedi A, et al. Crosstalk between Lys63- and Lys11-polyubiquitin signaling at
DNA damage sites is driven by Cezanne. Genes Dev. 2019;33: 1702-17.

236. Hu H, Haas SA, Chelly J, Van Esch H, Raynaud M, de Brouwer $\mathrm{AP}$, et al. X-exome sequencing of 405 unresolved families identifies seven novel intellectual disability genes. Mol Psychiatry. 2016;21:133-48.

237. Ng BG, Eklund EA, Shiryaev SA, Dong YY, Abbott MA, Asteggiano $\mathrm{C}$, et al. Predominant and novel de novo variants in 29 individuals with ALG13 deficiency: Clinical description, biomarker status, biochemical analysis, and treatment suggestions. J Inherit Metab Dis. 2020;43:1333-48.

238. Timal S, Hoischen A, Lehle L, Adamowicz M, Huijben K, Sykut-Cegielska J, et al. Gene identification in the congenital disorders of glycosylation type I by whole-exome sequencing. Hum Mol Genet. 2012;21:4151-61. 